Journal of Consumer Research, Inc.

From Inherent Value to Incentive Value: When and Why Pointless Effort Enhances Consumer Preference

Author(s): Sara Kim and Aparna A. Labroo

Source: Journal of Consumer Research, Vol. 38, No. 4 (December 2011), pp. 712-742

Published by: The University of Chicago Press

Stable URL: http://www.jstor.org/stable/10.1086/660806

Accessed: 07/08/2014 22:54

Your use of the JSTOR archive indicates your acceptance of the Terms \& Conditions of Use, available at http://www.jstor.org/page/info/about/policies/terms.jsp

JSTOR is a not-for-profit service that helps scholars, researchers, and students discover, use, and build upon a wide range of content in a trusted digital archive. We use information technology and tools to increase productivity and facilitate new forms of scholarship. For more information about JSTOR, please contact support@jstor.org. 


\title{
From Inherent Value to Incentive Value: When and Why Pointless Effort Enhances Consumer Preference
}

\author{
SARA KIM \\ APARNA A. LABROO
}

\begin{abstract}
Companies typically use clear fonts and bright pictures in their ads, Web sites, and product-package designs; place their products on easy-to-reach shelves; and emphasize ease-of-usage to make their products appear desirable to consumers. However, we suggest that customers focused on "incentive" value (getting the best product) may instead see products associated with noninstrumental (pointless) effort as more desirable. We suggest that because effort is usually required to get the best outcomes, people looking for the best outcomes also mistakenly presume effort must imply the best possible outcome. Across five studies, we show that highlighting incentive value-for instance, by message framing or by measuring chronic focus or by manipulating situational focus on incentive value-enhances preference toward outcomes associated with noninstrumental effort. We discuss the importance of our findings for understanding everyday consumption decisions and argue for a widespread tendency among individuals wanting the best to infer value from noninstrumental effort.
\end{abstract}

$\mathrm{C}$ ompanies typically associate objective ease with their products to make their products appear desirable to consumers. For example, online shopping malls promote userfriendly Web sites, software companies advertise ease in learning their software, and diet plans posit how easy it is to

Sara Kim is a doctoral student (skim12@chicagobooth.edu) and Aparna A. Labroo was an associate professor of marketing (alabroo@ chicagobooth.edu) at the Booth School of Business, University of Chicago, 5807 South Woodlawn Avenue, Chicago IL 60637. Starting July 1, 2011, Labroo is Chaired Professor of Marketing, Rotman School of Management, University of Toronto, 105 St. George Street, Toronto, ON M5S 3E6, Canada. The two authors contributed equally to this research, and authorship is presented alphabetically. We thank John Bullock, Kristopher Preacher, and Oleg Urminsky for discussions on issues pertaining to mediated moderation. Suggestions received at the annual meetings of the Association for Consumer Research Conference (2008), the Society for Consumer Psychology (2009), and the Haring Symposium (2010), and workshops at Northwestern University, Tulane University, University of Chicago, University of Toronto, and the Wharton Business School are gratefully acknowledged. We are deeply grateful to the editor, the associate editor, and the reviewers for insightful and constructive feedback. Address correspondence to Aparna A. Labroo.

John Deighton served as editor and Stijn Van Osselaer served as associate editor for this article.

Electronically published June 21, 2011 lose weight. Companies also evoke subjective ease by using bright, clear, large fonts and pictures in their ads, Web sites, and package designs; by paying premiums to place their products on central shelves; and by pulling their products forward rather than pushing them somewhat back on the shelf. Regardless of whether effort is real and objective or merely sensed and subjective, the dominant assumption among laypersons and across disciplines is that effort evokes negative feelings that make outcomes appear less attainable (more costly) and less desirable (e.g., poor quality, not enjoyable to use; Luce, Payne, and Bettman 1999; Payne, Bettman, and Johnson 1993; Schwarz 2004).

In the current article, we question this assumption and such practices. The meaning of effort associated with an outcome is ambiguous, and we propose that this meaning depends on the lens people adopt to represent value. In particular, we propose that value can be represented either as inherent value (how good or bad the outcome is) or as incentive value (whether the outcome is the best at serving a specific objective relative to other possibilities). In assessing the inherent value of an outcome, people consider the extent to which they like the outcome based on its attributes. In assessing incentive value, the frame of reference people instead adopt is whether the outcome is best at serving a specific objective relative to other alternatives. Existing research supports the idea that the value of any outcome, which is a positive function of attain- 
ability and of desirability of the outcome, can be represented either in terms of inherent (liking) or incentive (wanting) value (Berridge 1999; Dai, Brendl, and Ariely 2010; Naqvi, Shiv, and Bechara 2006; Winkielman and Berridge 2003). For the most part, these two types of value are positively associated because liking results in wanting, but the two can become dissociated when incentive value is highlighted (Frederick et al. 2009). The meaning of effort and its implication for outcome attainability and outcome desirability will depend on whether inherent value or incentive value is considered. To people considering inherent value, effort, which is affectively negative (Luce et al. 1999), will signal low attainability (high cost) and low desirability (e.g., product unfamiliarity, poor quality; Labroo and Lee 2006) of that outcome. However, to people considering incentive value-for instance, because of message framing, because of a person's chronic assessment tendency, or because of situational cues-effort will imply high motivational significance of the outcome (Labroo and Kim 2009a). Thus, effort will signal high attainability (if I put in effort, I will get this outcome) and high desirability (if I put in effort, it must be the best) of the outcome. As a consequence, all people some of the time and some people all of the time will systematically infer added value of outcomes that require an investment of more, not less, effort, even noninstrumental (pointless) effort. For instance, consumers considering incentive value may infer that the same product is more valuable because it will require a trip across town, its photograph in an advertisement is not entirely clear, or it is somewhat pushed back on a shelf rather than up front.

To summarize, we propose that the lens with which people construe value colors their interpretation of effort and its implications for attainability and for desirability (but not necessarily the decision weight of either; see fig. 1). We next discuss our framework. We then present five experiments as support. Finally, we discuss how our proposition presents a theoretical shift from consumer and psychological paradigms that presume that noninstrumental effort reduces value. From a practical point of view, we speculate that this phenomenon might underlie all kinds of consumer and social situations, including the inadequate appreciation for life's simpler pleasures by workaholics. Given the limited research in this area despite its importance, we argue for the merits of such research.

\section{THEORETICAL BACKGROUND}

\section{Effort and Value}

Almost all existing research in marketing and psychology suggests that ease (vs. effort) is positively related to perceived attainability and to perceived desirability of an outcome (Bornstein 1989; Schwarz 2004). For example, existing research suggests that effort associated with making complicated choices can evoke negative feelings (Botvinick, Huffstetler, and McGuire 2009; Hedgcock and Rao 2009; Luce et al. 1999; Thompson, Hamilton, and Petrova 2009). These negative feelings can be attributed to a high cost of attaining the outcome (Kivetz and Simonson 2003; Payne et al. 1993) and to unfamiliarity with, poor quality of, or unpleasantness of the outcome (Labroo and Lee 2006; Schwarz 2004), which can reduce product liking and increase choice deferral (Dhar 1997; Iyengar and Lepper 2000). For example, Whittlesea (1993) found that outcomes associated with effort were judged to be less abundant, and presumably, as a consequence, more costly to attain. In related research showing that effort can also make outcomes

\section{FIGURE 1}

THEORETICAL MODEL

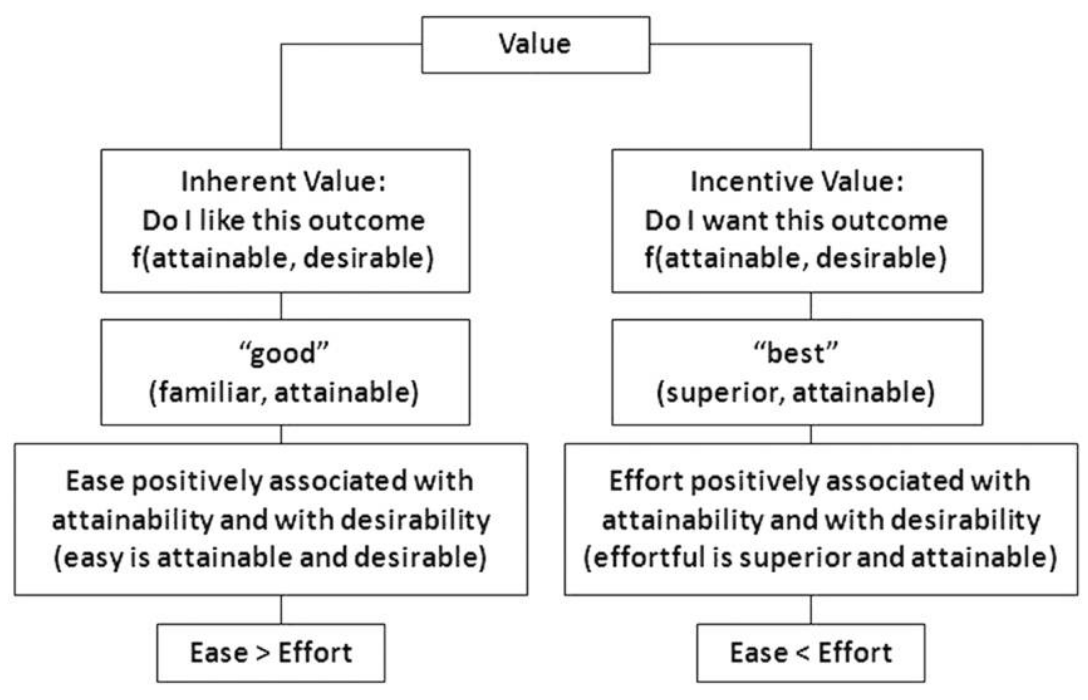


look undesirable, Iyengar and Lepper (2000) found that people are more likely to defer choice when presented with 24 rather than six variants of jam. Decision overload evoked negative feelings that were attributed to undesirability of the jams (jam attainability was never in question). Thus, objective effort has been found to make products look less attainable and less desirable. Also consistent with this idea that effort is affectively negative and is supposed to make outcomes appear less desirable, research shows that people feel a need to justify having expended effort (effort justification: Kruger et al. 2004; sunk cost effects: Soman 1998; Staw 1981), and after having expended effort, they justify choices made with effort as more favorable than those made without effort (cognitive dissonance: Festinger 1957). Effort expended on a prior task is even used as justification for engaging in a current task when the two tasks are seen as related. For instance, Tsai and McGill (2011) found that abstract thinkers (who are likely to see tasks as related) are more confident in a current task after expending effort on an earlier task (e.g., listing seven reasons vs. one reason for doing it) and that the extent to which the initial task is rated as effortful (and thus requiring justification) mediates confidence on the subsequent task.

Not only is objective effort affectively negative and to be minimized before and during exertion, as well as to be justified after exertion (sunk cost effect), but even subjective effort that arises from factors associated with merely thinking about the product, such as the effort necessary to process its features (e.g., blurriness of the features: Schwarz 2004), reduces liking of a product (Labroo, Dhar, and Schwarz 2008; Lee and Labroo 2004; Reber, Winkielman, and Schwarz 1998; Zajonc 1968). For example, Alter and Oppenheimer (2006) showed in a field study that stocks with fluent names do better in the short run. Short-run returns are defined as smaller, sooner-attainable rewards versus larger, later-attainable rewards, so presumably processing ease increased perceived attainability of returns. Additionally, in a meta-analysis of over 200 experiments, Bornstein (1989) showed that subjective feelings of ease, arising from any of a variety of sources-such as stimulus clarity, stimulus repetition, stimulus-background contrast, or priming - and applied to any of a variety of outcomes - assessing art, faces, animals such as dogs and fish, food, music, alphabets, and products-made those outcomes appear more desirable (also see Schwarz 2004). Thus, subjective ease can make products look more attainable and also more desirable. Related research additionally shows that products that feel subjectively easy to justify are considered more desirable and tend to be chosen more often (Sela, Berger, and Liu 2009; Simonson 1989) and that effort needed to think of more rather than few reasons to use a product can make the product feel less pleasant to use (Wänke, Bohner, and Jurkowitsch 1997).

However, other research is now instead beginning to recognize a positive relationship between value and effort, including anticipated or ongoing effort. Indeed, Briñol, Petty, and Tormala (2006) suggest that the impact of effort on evaluation should depend on the meaning people are overtly directed to assign to effort. For example, if people are told that unintelligent people like ease, outcomes associated with ease are judged less favorably. Labroo and Kim (2009a, 2009b) further demonstrated a first instance of one condition when effort is likely to spontaneously (without any explicit instructions being provided) take on a positive meaning with regard to value. Building on self-perception theory, which argues that people often infer their preferences from their actions (Bem 1967, 1972), Labroo and Kim (2009a) proposed that, because people usually put maximum effort into those means that are most effective for goal pursuit, a correlation exists in their minds between effort and effectiveness of a means for goal attainment. When trying to achieve a goal, people mistakenly reverse this correlation and, as a result, even noninstrumental effort signals that the product under consideration will best satisfy the accessible goal. Thus, to people who are in pursuit of important goals, "pointless" effort associated with an outcome can enhance the perceived value of the outcome by making it appear more instrumental for goal pursuit. In related research, Schrift, Netzer, and Kivetz (2011) show that individuals infer value from needless effort and complicate important choices, and Sela and Berger (2011) show that people also complicate unimportant choices. Labroo, Lambotte, and Zhang (2009) further suggest that noninstrumental effort signals value when people are assessing the uniqueness of information (see Galak and Nelson [2011] for similar arguments), and Pocheptsova, Labroo, and Dhar (2011) report that subjective effort can make special-occasion products appear more special. Using the case of instrumental effort, the exertion of which could actually result in better value, Kivetz and Simonson (2003) additionally show that people with an advantage relative to others in attaining an outcome infer that the outcome is more valuable when effort is needed to attain that outcome. Lo, Lynch, and Staelin (2007) show similar effects for even consumers facing a disadvantage relative to other consumers, provided those consumers are incentivized to buy the product.

\section{Inherent Value versus Incentive Value}

So how might these two sets of findings, one arguing that effort reduces value and the other that effort increases value, be reconciled? One perspective could be that less abundant outcomes are more desirable (i.e., scarcity heuristic, desirability $=f$ [attainability ${ }^{-}$; , Dai, Wertenbroch, and Brendl 2008). Effort signals low attainability (i.e., high cost; attainability $=f\left[\right.$ effort $\left.\left.^{-}\right]\right)$, and this low attainability in turn signals high desirability (i.e., desirability $=f\left[\mathrm{effort}^{+}\right]$). Value is a positive function of attainability and desirability

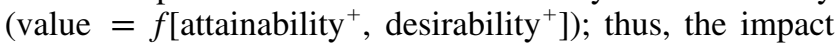
of effort on value depends on whichever of the two aspects of value a person assigns greater weight to (Tsai and McGill 2011). As a consequence, attainability-focused people report reduced value of the outcome because effort reduces perceived attainability, but desirability-focused people report increased value because effort increases perceived desirability.

However, this presumption is problematic for several rea- 
sons. Most importantly, it fails to account for at least 200 experiments that instead establish that ease (and not just effort) is positively linked to desirability (i.e., desirability = $f$ [effort ${ }^{-}$]; Bornstein 1989; Schwarz 2004). Many of those experiments employ stimuli such as abstract line drawings, abstract art, or animals such as fish, and it is questionable what attainability means in those contexts. Those experiments instead show that ease is affectively positive (Lee and Labroo 2004; Winkielman and Cacioppo 2001), and the positive affect arising from ease is attributed to the desirability of such decision targets (Schwarz 2004). The proposition also does not account for evidence that suggests that effort can relate positively to attainability (attainability $=$ $f\left[\mathrm{effort}^{+}\right.$) and not just negatively to it as presumed. For example, highly motivated people boost effort in the face of difficulty to motivate persistence toward the outcome (e.g., if I put in effort, I will get it; Taylor and Brown 1988). It is also not clear what would cause people to weight either on attainability or on desirability when a basic assumption is that the two are negatively correlated and not independent of each other (the assumption is that effort increases desirability by first signaling low attainability). In sum, the presumptions that highly attainable outcomes are always less desirable (they are not), that ease always conveys high attainability but low desirability (it does not), and that the impact of ease on value depends on whichever aspect of value is weighted more (it cannot) are simply not tenable: according to the literature, ease is positively and negatively related to desirability, ease is positively and negatively linked to attainability, and highly attainable outcomes can be more or less desirable.

Thus, to reconcile these mixed findings pertaining to the effect of effort on value, we propose an alternative framework, derived from recent research that distinguishes between inherent (liking) value and incentive (wanting) value. Inherent value pertains to whether an outcome feels good or bad, whereas incentive value is conceptualized in terms of motivational relevance and whether the outcome is best suited relative to others to fulfill one's current motivations (Berridge 1999; Dai et al. 2010; Naqvi et al. 2006; Winkielman and Berridge 2003). In general, liking and wanting map onto each other because liking usually results in wanting. However, we propose that when the incentive value of an outcome is highlighted, these two types of value can become dissociated from each other. For example, Litt, Khan, and Shiv (2010) show that in some situations, a failure to attain an outcome can result in more wanting but less liking for the outcome, and Dai et al. (2010) show that men demonstrate increased wanting but not increased liking of more attractive women when they have to work harder to view their pictures.

We propose that in the vast majority of studies arguing that ease increases outcome value, it is possible that people were considering the inherent value of the outcome. Among people considering inherent value (outcome goodness), positive feelings of ease (Winkielman and Cacioppo 2001) are likely to make the outcome feel more attainable, familiar, self-relevant, of high quality, and desirable (Bornstein 1989; Schwarz 2004) and hence increase value. However, studies showing that effort is positively associated with value appear to implicate incentive value: consumers are considering whether the outcome is the best possible relative to other means that satisfy a specific goal (Labroo and Kim 2009a), best specific relative to what others might attain (Kivetz and Simonson 2003; Lo et al. 2007), or the most novel and best serving a specific special occasion (Labroo et al. 2009; Pocheptsova et al. 2011). If so, it is possible that whenever incentive value (wanting the best) is highlighted, as might happen when decision framing makes a person consider whether the outcome is best for one's specific needs, when people chronically think of themselves as deserving of the best outcomes, or because situational cues prompt them to think in such a manner, both attainability and desirability could become positively associated with effort. In incentive terms, effort suggests that the outcome is the best and the most desirable, and a sense of ongoing effort makes motivated people more optimistic about the possibility of attaining the outcome.

\section{The Current Research}

To summarize, we propose that effort is a positive cue to people considering incentive value (whether the outcome is among the best possible) but that it is a negative cue in general to people who may be considering inherent value (whether the outcome is any good). Some research indeed shows that, for the most part, people appear to consider how much they like a product without sufficient consideration to whether the option best serves their motivations relative to other possibilities (Frederick et al. 2009). Across five experiments, we show that when incentive value (wanting the best outcomes) is highlighted to consumers-by message framing focused on wanting the best product (experiment 1), because of a chronic tendency to focus on incentive value (experiments $2 \mathrm{~A}$ and $2 \mathrm{~B}$ ), or because of situational cues known to make people want the best outcomes (experiments 3 and 4) - they prefer outcomes associated with effort (vs. ease). We show that our framework holds when consumers anticipate objective (physical) effort (experiments 1 and 4) and when we employ subjective effort (a clear vs. blurry ad/product mock up; experiments 2A, 2B, and 3). Our framework applies to the social domain (relationship partners), the consumer domain (product choice), consumption planning (which store has a better product), and doing social good (making donations). Furthermore, our framework holds regardless of how incentive value is highlighted-more overtly and directly through message framing (experiment 1) or manipulated or measured in a subtle manner (experiments 2A, 2B, 3, and 4).

\section{EXPERIMENT 1: PLANNING ON GOING THE EXTRA MILE(S)}

Experiment 1 employed a 2 (value focus: inherent vs. incentive) $\times 2$ (objective effort: low vs. high) between-subjects design in which participants evaluated a bottle of wine. Fifty-one city residents read a scenario (see fig. A1 in app. A) in which they were searching for the best possible bottle 
TABLE 1

THE EFFECT OF FOCUS AND EFFORT ON PREFERENCES: SUMMARY RESULTS

\begin{tabular}{|c|c|c|c|c|c|c|}
\hline & \multicolumn{3}{|c|}{ High control (incentive focus) } & \multicolumn{3}{|c|}{ Low control (inherent focus) } \\
\hline & Ease & Effort & Effort + source & Ease & Effort & Effort + source \\
\hline \multicolumn{7}{|l|}{ Study $1(n=51)$ : } \\
\hline Evaluation of wine & $\begin{array}{l}4.64 \\
(.28)\end{array}$ & $\begin{array}{l}5.72 \\
(.28)\end{array}$ & & $\begin{array}{l}6.07 \\
(.25)\end{array}$ & $\begin{array}{l}5.14 \\
(.28)\end{array}$ & \\
\hline \multicolumn{7}{|l|}{ Study 2A $(n=66)$ : } \\
\hline Evaluation of woman & 3.50 & 4.07 & & 4.14 & 3.61 & \\
\hline \multicolumn{7}{|l|}{ Study $2 \mathrm{~B}(n=80)$ : } \\
\hline $\begin{array}{l}\text { Evaluation of cereal } \\
\text { Study } 3(n=60) \text { : }\end{array}$ & 4.95 & 5.96 & & 5.61 & 4.64 & \\
\hline Cookie evaluation & $\begin{array}{c}3.52 \\
(.26)\end{array}$ & $\begin{array}{c}5.36 \\
(.29)\end{array}$ & & $\begin{array}{c}5.37 \\
(.27)\end{array}$ & $\begin{array}{c}3.75 \\
(.26)\end{array}$ & \\
\hline Cookie attainability & $\begin{array}{l}3.47 \\
(.29)\end{array}$ & $\begin{array}{l}4.15 \\
(.32)\end{array}$ & & $\begin{array}{l}3.90 \\
(.30)\end{array}$ & $\begin{array}{l}2.19 \\
(.29)\end{array}$ & \\
\hline Cookie superiority & $\begin{array}{c}3.79 \\
(.30)\end{array}$ & $\begin{array}{c}4.92 \\
(.33)\end{array}$ & & $\begin{array}{c}4.64 \\
(.31)\end{array}$ & $\begin{array}{c}4.23 \\
(.30)\end{array}$ & \\
\hline \multicolumn{7}{|l|}{ Study $4(n=74)$ : } \\
\hline Donation rate $(n=74)$ & $\begin{array}{l}.5385 \\
(.12)\end{array}$ & $\begin{array}{l}.9231 \\
(.12)\end{array}$ & $\begin{array}{l}.5833 \\
(.13)\end{array}$ & $\begin{array}{l}.7692 \\
(.12)\end{array}$ & $\begin{array}{l}.5833 \\
(.13)\end{array}$ & $\begin{array}{l}.7273 \\
(.13)\end{array}$ \\
\hline Donation cents $(n=51)$ & $\begin{array}{l}46.43 \\
(10.80)\end{array}$ & $\begin{array}{l}83.33 \\
(8.30)\end{array}$ & $\begin{array}{l}67.86 \\
(10.80)\end{array}$ & $\begin{array}{l}77.50 \\
(9.10)\end{array}$ & $\begin{array}{c}42.86 \\
(10.80)\end{array}$ & $\begin{array}{l}65.63 \\
(10.10)\end{array}$ \\
\hline Charity evaluation $(n=74)$ & $\begin{array}{c}4.23 \\
(.30)\end{array}$ & $\begin{array}{c}6.15 \\
(.30)\end{array}$ & $\begin{array}{c}4.58 \\
(.31)\end{array}$ & $\begin{array}{c}5.69 \\
(.30)\end{array}$ & $\begin{array}{c}3.63 \\
(.31)\end{array}$ & $\begin{array}{c}5.68 \\
(.33)\end{array}$ \\
\hline
\end{tabular}

NотE.-Standard errors are in parentheses.

of wine. To highlight incentive value (getting the best wine), roughly half of the participants were told they were considering whether the wine truly would be among the best and worthy of going to the store for. To the remainder of the participants, we suggested that they were already sure the wine was exceptional and likely to be their chosen one, thereby removing the necessity to further consider whether it is the best possible. Next, to manipulate effort, roughly half of the participants read that the store was down the road (ease), and the rest read that it was halfway across town (effort). After reading the scenario, participants evaluated the wine (like, favorable, likely to buy; $1=$ not at all, $7=$ very; $\alpha=0.81$ ), completed effort manipulation checks (Going to the store is effortful, bothersome; $1=$ not at all, 7 $=$ very; $\alpha=0.81$ ), value framing manipulation-checks (My focus is on . . .; $1=$ how it will feel to get this wine, 7 $=$ getting the best wine), interspersed between control measures (I am the kind of person who usually buys exceptional gifts for others; $1=$ not at all, $7=$ very much; attention to the task: $1=$ little attention, $7=$ a lot of attention; mood: 1 = feel bad, 7 = feel good). We expected that people assessing whether the wine was the best possible (incentive value) would evaluate the wine more favorably in a distant (vs. close) store. People no longer assessing if the wine is the best possible would instead be more attuned to the affective aspects of value and effort, evaluating the wine less favorably in a distant (vs. close) store.

A 2 (focus) $\times 2$ (effort) ANOVA on the effort manipulation check revealed the expected main effect of effort $\left(M_{\mathrm{far}}=4.17, M_{\text {close }}=2.25 ; F(1,47)=25.74, p<.01\right.$; other $F$ 's $<1)$. Also, a $2 \times 2$ ANOVA on the focus manipulation check revealed the expected main effect of focus
$\left(M_{\text {incentive }}=5.06, M_{\text {inherent }}=4.17 ; F(1,47)=4.29, p<.05\right.$; other $F$ 's $<1)$. No significant effects were observed on any of the control variables (general gift purchasing tendency, mood, and attention; $F$ 's $<1$ ). However, a 2 (focus) $\times 2$ (effort) ANOVA on wine evaluation, our key dependent variable, revealed a significant interaction $(F(1,47)=$ $13.18, p<.01$; see table 1$)$. Inherent-value-focused participants evaluated the wine more favorably when effort was low $\left(M_{\text {close }}=6.07, M_{\text {far }}=5.14 ; t(47)=2.43, p<.05\right)$, but incentive-focused participants evaluated the wine more favorably when effort was high $\left(M_{\mathrm{far}}=5.72, M_{\text {close }}=4.64\right.$; $t(47)=2.70, p=.01)$. Thus, consumers evaluate products they can get easily more favorably when value is construed as liking but less favorably when value is construed as getting the best. Notably, the product was identical in both cases, and we manipulated the value focus of the consumer.

Readers may wonder whether the mediating effect of perceived effort on evaluation is moderated by value focus. (See app. B.) Employing exact regression procedures used by Tsai and McGill (2011), we found an effect of objective effort on perceived effort $\left(b_{51}=0.98, \mathrm{SE}=0.19 ; t(47)=\right.$ $5.16, p<.01)$ and an effect of objective effort $\times$ focus on evaluation $\left(b_{43}=0.50, \mathrm{SE}=0.14 ; t(47)=3.63, p<.01\right)$ in the basic model. When perceived effort was included to run an overall model, the effect of objective effort on evaluation decreased in significance $\left(b_{63}=0.27, \mathrm{SE}=0.18\right.$; $t(45)=1.49, p>.14)$, and instead the effect of perceived effort $\times$ focus on evaluation was significant $\left(b_{65}=0.10\right.$, $\mathrm{SE}=0.05 ; t(45)=1.86, p=.06$; Sobel $z=1.75, p=$ $.05)$. This mediation suggests that value framing moderates whether effort exerts a positive or negative impact on value. However, as with any mediation analysis that is based using 
a manipulation check of the independent variable as mediator, this moderated mediation should be interpreted with caution. This analysis does establish that the perceived effort underlies the effect of distance on evaluation rather than something else that distance could be manipulating (e.g., construal, beliefs about store quality). However, it does not provide any process evidence as to whether the value frame affected the nature of the inference pertaining to the level of attainability versus superiority (whether this outcome is the best) that people might make. We test the nature of inference as underlying process in experiments 3 and 4 . A second concern with this analysis is that it opens up the possibility that the results are explained by effort justification; that is, it is plausible that people planning to expend effort might infer that they must be expending effort because the wine is best. Our results, if anything, offer evidence opposite to such a claim. First, people focused on inherent value are the ones committed to wine purchase, but people focused on incentive value were still considering whether to commit to a purchase. Thus, if anything, those who had committed should have at least as much if not more need to justify effort they know they will be expending (they did not) compared to those who are still considering whether to commit to purchase (incentive focus). Second, these results only held using unconventional mediation procedures employing manipulated variables in the interaction term of the basic model but measured variables in the interaction terms of the full model, per Tsai and McGill (2011), which we do not recommend.

An implication of these findings is that marketers should not always make their products easily available to consumers and that consumers might sometimes infer value from a challenge of having to exert effort to get the product. The data also suggest that marketers whose products require the consumer to exert effort should focus their consumers on why the product is among the best over easily accessible products in the market. One way marketers can do so is to directly manipulate consumer focus, just as we did in experiment 1 . Another way is to find consumer segments that might have chronic focus on incentive value. One such group, we propose, may be people who believe they have high outcome controllability, defined as a real or illusory belief in one's ability to influence one's outcomes (Bandura 1977). Low control is shown to result in affective concerns pertaining to whether an outcome is attainable and is any good (Bandura 1977; Langer 1975, 313), which are likely to correspond with liking. Instead, high control appears to result in a focus on incentive value: it enhances a sense of entitlement and thinking of oneself as above average and more deserving than others of the best outcomes (Ehrlinger and Dunning 2003; Gollwitzer and Kinney 1989; Kruger and Dunning 1999; Taylor and Brown 1988). Thus, to test our proposition that high outcome control increases incentive focus and thus such individuals will likely evaluate outcomes associated with effort more favorably, in experiments $2 \mathrm{~A}$ and $2 \mathrm{~B}$ we measure outcome controllability and in experiments 3 and 4 we manipulate it.

\section{EXPERIMENT 2A: SMOOTH TALKER OR SHY GAWKER?}

To test our theory that people who are chronically focused on incentive value (getting the best outcome) perceive the very same outcome more favorably if it involves noninstrumental effort, we investigated whether those unattached heterosexual males who think of themselves as deserving of the best girl end up with more positive attitudes toward the very same woman if they feel a subjective sense of effort while evaluating her. For instance, might such men judge a woman as more desirable if they exert token effort and strain their eyes to see her, as they might when looking at a picture that is matted rather than glossy, or in sepia rather than color, or because she is standing across the room rather than next to them?

Sixty-six single heterosexual males completed this experiment on the computer. They first indicated their perceived control over "getting the girl" in a social interaction, using a seven-item Flirting Superiority Scale (FSS) we developed (see fig. A2 in app. A; $\alpha=.88$; from Communicative Adaptability Scale [CAS], Duran [1992]). The measures tap into a person's belief that he is in control of and can influence his flirting outcomes to get the best ones possible. Past research suggests that high outcome controllability could be an effective manipulation of incentive focus (entitlement toward getting the best outcomes; Taylor and Brown 1988). A pretest $(n=27)$ confirmed that high-FSS participants derive value from getting the best outcome (When talking with a woman, I consider whether . . .; 0 $=$ she is nice, $1=$ she is the best; $M_{+50 \%}=71.4 \%, M_{-50 \%}$ $\left.=15.4 \%, b=1.39, \mathrm{SE}=0.55 ; \chi^{2}(1)=6.26, p=.01\right)$. As control measures, participants also provided measures of self-esteem $(\alpha=.82)$ and of general communication competence $(\alpha=.76)$.

Next, participants were presented with the picture of a woman, which was either clear (ease condition) or blurred by a small percentage (effort condition; see fig. A3 in app. A), and they were asked to provide their attitudes toward the woman (attractive, favorable, good; $\alpha=.70 ; 1=$ not at all, $7=$ very). As an effort manipulation check, participants indicated how effortful it was to process the picture ( $1=$ clear, easy; 7 = blurry, difficult to judge; $r=0.62$ ). Studies show that subjective effort manipulated in this manner is attributed to whatever decision a person is making at the moment (Briñol et al. 2006); thus, in our experiment, effort should be interpreted in line with a participant's value focus. As an additional control measure, participants were shown the picture of a man that was also either clear or blurry and were asked to evaluate the man (attractive, favorable, good; $\alpha=.81 ; 1=$ not at all, $7=$ very). Notably, high-FSS participants (heterosexual males) should not associate incentive value with such a target and thus should evaluate the male target based on whether or not they like the person. Finally, we collected reports of $\operatorname{mood}(1=\mathrm{bad}$, $7=\operatorname{good})$, arousal $(1=$ depressed, $7=$ excited $)$, and attention $(1=$ little, $7=$ a lot $)$. 


\section{Results}

Regression analysis conducted on the effort manipulation check measures with picture type, FSS, and their interaction as independent variables revealed only the expected main effect of picture type $\left(M_{\text {blurry }}=4.19 ; M_{\text {clear }}=3.29 ; b=\right.$ $-.44, \mathrm{SE}=.14 ; t(62)=-3.13, p<.01)$. Regression analyses on each of the control variables (attitude toward the man, general communication competence, self-esteem, mood, arousal, and attention) with picture type, FSS, and their interaction as independent variables revealed no significant effects (all $p$ 's $>.20$ ), except for self-esteem, which was positively correlated with FSS $(b=.35, \mathrm{SE}=.11$; $t(62)=3.34, p<.01)$, and general communication competence, which was also positively correlated with FSS $(b$ $=.30, \mathrm{SE}=.08 ; t(62)=3.85, p<.01)$, but both selfesteem and communication competence do not predict our dependent variable, attitudes toward the woman (all $p$ 's $>$ .70).

\section{Hypothesis Testing}

Regression analysis on attitude toward the woman with picture type, FSS, and their interaction as independent variables revealed only the predicted interaction $(b=-.23$, $\mathrm{SE}=.09 ; t(62)=-2.63, p<.01$; see table 1$)$. Spotlight analysis showed that participants with low FSS ( -1 SD) had more favorable attitudes when the picture was clear $\left(M_{\text {clear }}=4.14 ; M_{\text {blurry }}=3.61 ; t(62)=1.81, p<.05\right)$, but those with high FSS $(+1 \mathrm{SD})$ had more positive attitudes when the picture was blurry $\left(M_{\text {blurry }}=4.07 ; M_{\text {clear }}=3.50\right.$; $t(62)=-1.94, p<.05)$. Note that normatively a blurry picture is worse than a clear one, but ironically males reporting higher flirting skill desired the same woman more when they saw a worse picture of her.

\section{EXPERIMENT 2B: THE SHOPPER SUPERIORITY PARADOX}

To investigate whether subjective effort increases evaluation of products among consumers who think of themselves as superior shoppers (getting the best products), we conducted a field study with 80 residents in a downtown area. First, we asked each respondent to look at and evaluate either a clear or a blurry product mock-up of 365 Cereal Bar (Whole Foods Brand; see fig. A3 in app. A), presumably a new product in the market (favorable, likable, likely to buy; $1=$ not at all, $7=$ very; $\alpha=.87)$. They also indicated their $\operatorname{mood}(1=\operatorname{bad}, 7=\operatorname{good})$, arousal $(1=$ unexcited, $7=$ excited $)$, and attention $(1=$ paid little, $7=$ paid a lot of $)$. Finally, we measured each respondent's perceived shopping skill (see fig. A2 in app. A; $\alpha=.71$; Shopping Superiority Scale [SSS] based on Mallalieu and Palan [2006]). Regression on each of the controls (mood, arousal, and attention) with mock-up, SSS, and their interaction as independent variables revealed no effects ( $p$ 's $>.20)$. A pretest confirmed that the focus of high-SSS consumers $(n=33)$ is on incentive value (When buying products, I focus on . . .; 0
= familiar likeable products, $1=$ only the best; $M_{+50 \%}=$ $53.0 \%, M_{-50 \%}=37.5 \% ; b=0.75, \mathrm{SE}=0.40 ; \chi^{2}(1)=$ $3.39, p=.05)$.

Regression analysis on attitude toward 365 Cereal Bar with mock-up type, SSS, and their interaction as independent variables revealed the predicted interaction $(b=-.46$, $\mathrm{SE}=.13 ; t(76)=-3.63, p<.01$; see table 1$)$. Spotlight analysis showed that participants with low SSS (-1 SD) evaluated the cereal bars more favorably when they saw the clear mock-up $\left(M_{\text {clear }}=5.61, M_{\text {blurry }}=4.64 ; t(76)=2.34\right.$, $p<.05)$, but participants with high SSS (+1 SD) evaluated the cereal bars more favorably when the mock-up was blurry $\left(M_{\text {blurry }}=5.96, M_{\text {clear }}=4.95 ; t(76)=-2.48, p<.01\right)$. Note that the effort was token and not real: we created it by altering the subjective processing experiences associated with the product mock-up. Marketers presumably can associate effort with their products by the use of pastel rather than bright colors or by placing the product high up or somewhat back on a shelf rather than at eye level. Ironically, by creating such challenges in a shopping experience, we expect that marketers can increase sales among shoppers who feel in control of their shopping experience. Less surprisingly, the reverse is likely to be true of shoppers who are overwhelmed by their shopping experience.

Experiment 1 directly manipulated focus on incentive value to investigate peoples' preferences for products associated with real effort (vs. ease). Experiments $2 \mathrm{~A}$ and 2B measured chronic controllability, which is known to evoke focus on getting the best outcomes (incentive value), and they found results similar to those observed in experiment 1. People who feel deserving of the best outcomes, for instance, because they are early adopters (pioneers) or trendsetters, might be naturally more inclined to have their focus on best outcomes (and see value in products associated with noninstrumental effort). In experiment 3 , we replicate the findings of experiments $2 \mathrm{~A}$ and $2 \mathrm{~B}$ but instead manipulate value focus using an illusory control manipulation (Langer 1975), known to result in entitlement and deservingness of the best outcomes (Gollwitzer and Kinney 1989; Kruger and Dunning 1999; Taylor and Brown 1988), which may correspond with focus on incentive value (wanting the best outcomes).

\section{EXPERIMENT 3: ILLUSIONS OF A COOKIE MONSTER}

Experiment 3 employed a 2 (value focus: inherent vs. incentive) $\times 2$ (objective effort: low vs. high) between-subjects design in which a box of assorted cookies served as the target product. Sixty undergraduate students participated for compensation. Value focus was operationalized by an illusory control manipulation and effort was operationalized by a perceptual illusion. Upon arrival at the lab, we seated each participant individually at a rectangular table. In advance, we placed a box of cookies on the table 3 feet away from where the participant would sit. 


\section{Focus Manipulation}

At the start of the experiment, each participant received a lottery ticket that would determine whether he would get the box of cookies in front of him. Adapting classic manipulations showing that people believe they have higher control over obtaining a positive outcome when they roll a die than when an experimenter rolls the die (Langer 1975), and based on the finding that high control results in enhanced sense of deservingness and entitlement of the best outcomes (Kruger and Dunning 1999; Taylor and Brown 1988), and based on the observation that some (but not all) real-world lotteries allow participants to choose their numbers, which we proposed might focus participants on incentive value, we asked half of the participants to include their winning number on the ticket (incentive value focus). The remaining participants received a number already on the ticket (baseline/low control). Manipulating this factor might be in a marketer's control; for instance, in his advertising, a marketer could cue consumers to think about their own versus the marketer's actions that affect choices. Presumably, consumer focus on own actions would result in higher outcome control. A pretest $(n=30)$ confirmed that writing one's own lottery number shifts focus to wanting the best outcomes (I value . . . ; $0=$ cookies I like, $1=$ cookies that are exceptional; $M_{\text {high }}=64.3 \%, M_{\text {low }}=31.3 \% ; \chi^{2}(1)=$ $3.28, p=.05)$.

\section{Effort Manipulation}

To associate effort with the box of cookies, we created a perceptual illusion. In the high-effort condition, experimenters placed a dull white screen (that blended with the color of the box of cookies) directly behind the box of cookies. The screen essentially truncated the table and made the box appear to be at the far end of the table. In contrast, in the low-effort condition, experimenters placed the screen 3 feet behind the box of cookies toward the end of the table. This placement made the box appear to be in the middle of the table and visually closer to the participant. We used this manipulation in order to replicate the kinds of product shelving situations a consumer might face. In sum, although the physical distance between the participant and the box of cookies was constant across conditions ( 3 feet), by placing the screen either directly behind or 3 feet behind the cookies, we manipulated a perception of effort associated with the box of cookies. A pilot $(n=22)$ confirmed the link between effort and the position of the screen (the cookies appear: 1 $=$ easy to process, $7=$ effortful to process; $M_{\text {front }}=4.75$ vs. $\left.M_{\text {end_table }}=3.90 ; t(20)=2.45, p<.05\right)$.

\section{Dependent Variables}

Next, each participant received a survey questionnaire. First, to measure perceived level of attainability of the cookies, each participant indicated his confidence in winning the cookies $(1=$ not at all confident, unlikely, $7=$ very confident, likely to win cookies; $\alpha=0.91)$. To measure per- ceived level of superiority (desirability) of the cookies, each participant indicated taste and product superiority $(1=$ seems inferior tasting, are not the best, will not make me feel good; $7=$ seems superior tasting, are the best quality, will make me feel good; $\alpha=0.71$ ). Finally, each participant evaluated the cookies (favorable, likable, positive; $1=$ not at all, $7=$ very; $\alpha=0.91$; attitude measures counterbalanced with attainability/superiority measures and were always on consecutive pages; no order effects were observed). To test for alternative underlying processes and to rule against self-generated validity effects, participants indicated the importance of indulgence goals (e.g., to control for a possibility that effort reduced value of indulgence; $1=$ Feeling good is less important than self-control, $7=$ Feeling good is more important than self-control), their attitude toward cookies in general (In general, I like cookies; $1=$ disagree, $7=$ agree), attention paid to the task (e.g., to control for an alternative account that subjective effort increased involvement; $1=$ little attention, $7=$ a lot of attention), current mood (e.g., to control for an alternative account that subjective ease induced positive mood; $1=$ bad, $7=\operatorname{good})$, and arousal $(1=$ unexcited, $7=$ excited $)$.

\section{Results}

The 2 (focus) $\times 2$ (effort) ANOVAs on each of the control measures (importance of indulgence goals, general liking of cookies, self-reported attention to the task, selfreported mood, and self-reported arousal) revealed no significant effects (all $p$ 's $>.20$; see table 2 for means).

Hypothesis Testing. A 2 (focus) $\times 2$ (effort) betweensubjects ANOVA on attitude toward the cookies only revealed a significant interaction $(F(1,56)=39.71, p<.01$; see fig. 2 and table 1). As expected, low-control (baseline) participants who were assigned a lottery number preferred the cookies associated with ease $\left(M_{\text {ease }}=5.37, M_{\text {effort }}=\right.$ $3.75 ; t(56)=4.27, p<.01$ ), but high-control (incentive focus) participants preferred the cookies associated with effort $\left(M_{\text {ease }}=3.52, M_{\text {effort }}=5.36 ; t(56)=4.64, p<.01\right)$.

Cookie Attainability. A 2 (focus) $\times 2$ (effort) ANOVA on an index created by averaging the two attainability items revealed a main effect of control $(F(1,56)=6.60, p<.01)$; those who indicated their own lottery number thought the cookies were more attainable $(M=3.81)$ than did those who were assigned a number $(M=3.04)$. The main effect of effort was marginal $(F(1,56)=2.96, p<.10)$; cookies were perceived as more attainable when close $(M=3.68)$ versus far $(M=3.17)$. Importantly, a significant interaction between focus and effort $(F(1,56)=16.09, p<.01$; see fig. 2) qualified these main effects. For low-control (baseline) participants, effort reduced perceived level of cookie attainability $\left(M_{\text {ease }}=3.90, M_{\text {effort }}=2.19 ; t(56)=4.13, p\right.$ $<.01$ ), as one might expect. In contrast, among high-control (incentive focus) participants, effort had a (nonsignificant) tendency to increase perceived level of cookie attainability $\left(M_{\text {ease }}=3.47, M_{\text {effort }}=4.15 ; t(56)=1.59, p>.12\right)$. 
TABLE 2

EFFECT OF FOCUS AND EFFORT ON CONTROL VARIABLES: SUMMARY RESULTS

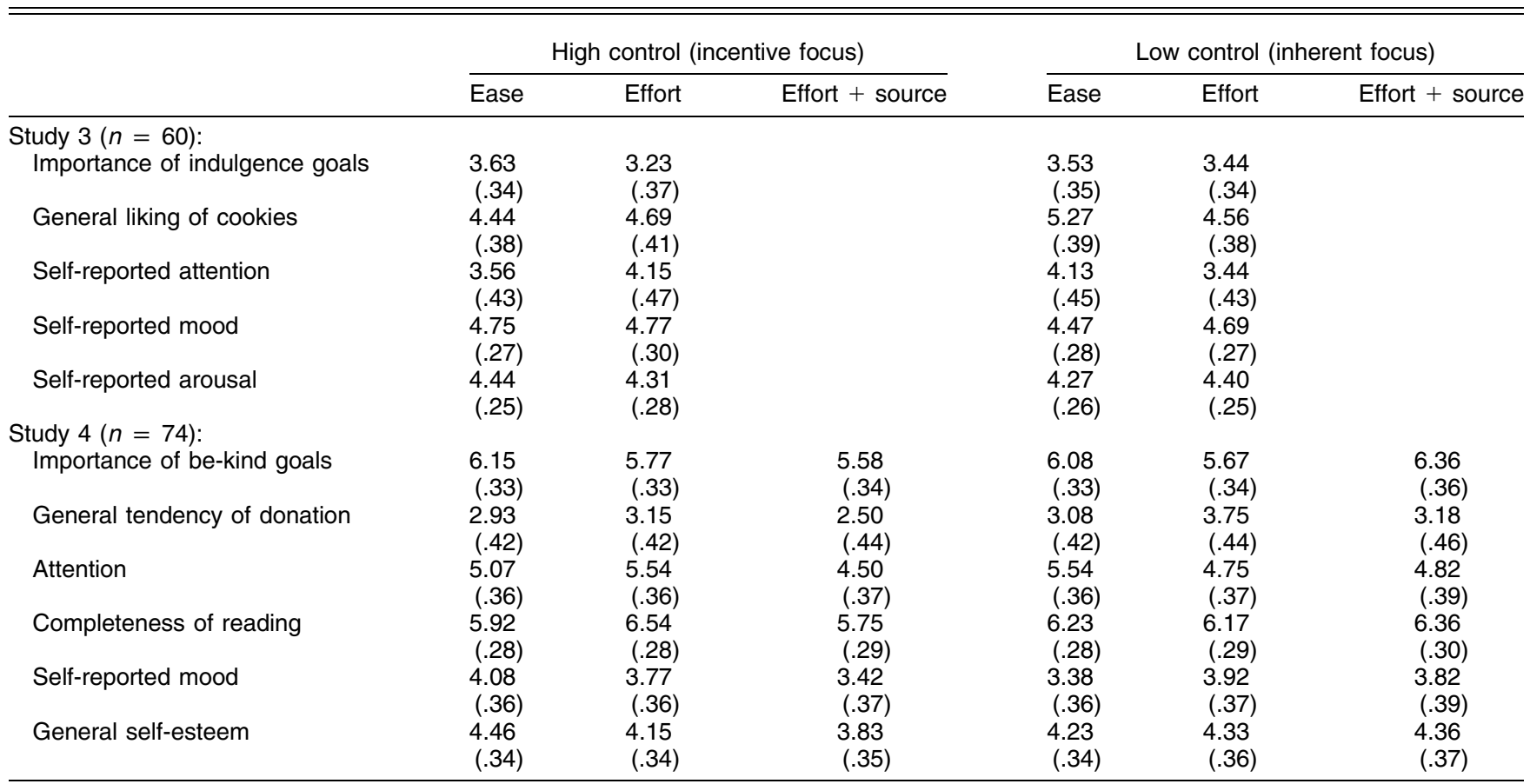

NOTE.-Standard errors are in parentheses.

Cookie Superiority. A 2 (focus) $\times 2$ (effort) ANOVA on the index created by averaging the three items reflecting superiority of the cookies revealed only a significant interaction $(F(1,56)=6.11, p<.05$; see fig. 2$)$. Among highcontrol (incentive focus) participants, ease reduced perceived cookie superiority $\left(M_{\text {effort }}=4.92, M_{\text {ease }}=3.79 ; t(56)\right.$ $=2.51, p=.01$ ), but among low-control (inherent value focus) participants, effort had a (nonsignificant) tendency to reduce perceived cookie superiority $\left(M_{\text {effort }}=4.23, M_{\text {ease }}=\right.$ 4.64; $t<1)$.

Mediated Moderation. To test for underlying process (Preacher, Rucker, and Hayes [2007], model 5, 194), we ran four simultaneous regressions (see table 3): (1) evaluation $=f$ (effort, focus, effort $\times$ focus), (2) attainability level $=$ $f$ (effort, focus, effort $\times$ focus), (3) superiority level $=f$ (effort, focus, effort $\times$ focus); and (4) evaluation $=f$ (effort, focus, effort $\times$ focus, attainability level, attainability level $\times$ focus, superiority level, superiority level $\times$ focus). In the results, we observed a significant effect of effort $\times$ focus on evaluation in equation $1(b=0.87, \mathrm{SE}=0.14 ; t(56)$ $=6.30, p<.01$ ), a significant effect of effort $\times$ focus on attainability level in equation $2(b=0.60, \mathrm{SE}=0.15 ; t(56)$ $=4.01, p<.01)$, a significant effect of effort $\times$ focus on superiority level in equation $3(b=0.39, \mathrm{SE}=0.16 ; t(56)$ $=2.47, p<.05)$, and significant effects of attainability level $(b=0.29, \mathrm{SE}=0.10 ; t(52)=2.86, p<.01$; Sobel $z=$ 2.33, $p<.01)$ and superiority level $(b=0.47, \mathrm{SE}=0.10$; $t(52)=4.48, p<.01$; Sobel $z=2.16, p<.05)$ but reduced significance for the effect of effort $\times$ focus on evaluation in equation $4(b=0.49, \mathrm{SE}=0.14 ; t(52)=3.60, p<$ $.01)$. Thus, attainability level and superiority level jointly mediated the effect of effort $x$ focus on evaluation. (Note: the INDIRECT command controls for any correlations between terms and gives an output similar to LISREL when items are uncorrelated; see apps. C-F.)

This analysis suggests that the focus $\times$ effort moderation effect on evaluation is mediated by the meaning people assign to effort according to their value focus (see app. C, figs. $\mathrm{C} 1$ and $\mathrm{C} 2$, model A). Effort either has a positive effect on attainability and on superiority or a negative effect on attainability and on superiority depending on how value is construed. An interpretation that effort always evokes each of two inversely related meanings pertaining to level of attainability and superiority but the weight that people put on either cue depends on focus (model B) or that the effect of focus $\times$ effort on evaluation depends both on the meaning people assign to effort and a shift in decision weight according to focus (model C) is not plausible. For these alternative models/accounts, the two interactions of focus $\times$ attainability level and focus $\times$ superiority level would need to be significant, which they are not (in accordance with model A).

Conceptual Implications: Does the Evidence Support Two Representations of Value? Empirically, the data support model A (see app. C, figs. C1 and C2, models A-C). Conceptually, model $\mathrm{A}$ is inconsistent with an assumption that there is a singular representation of value that is the weighted sum of perceived attainability and desirability of an outcome 
FIGURE 2

THE EFFECT OF FOCUS (CONTROL) AND EFFORT ON COOKIE EVALUATION (TOP), ATTAINABILITY LEVEL (MIDDLE), AND SUPERIORITY LEVEL (BOTTOM): EXPERIMENT 3
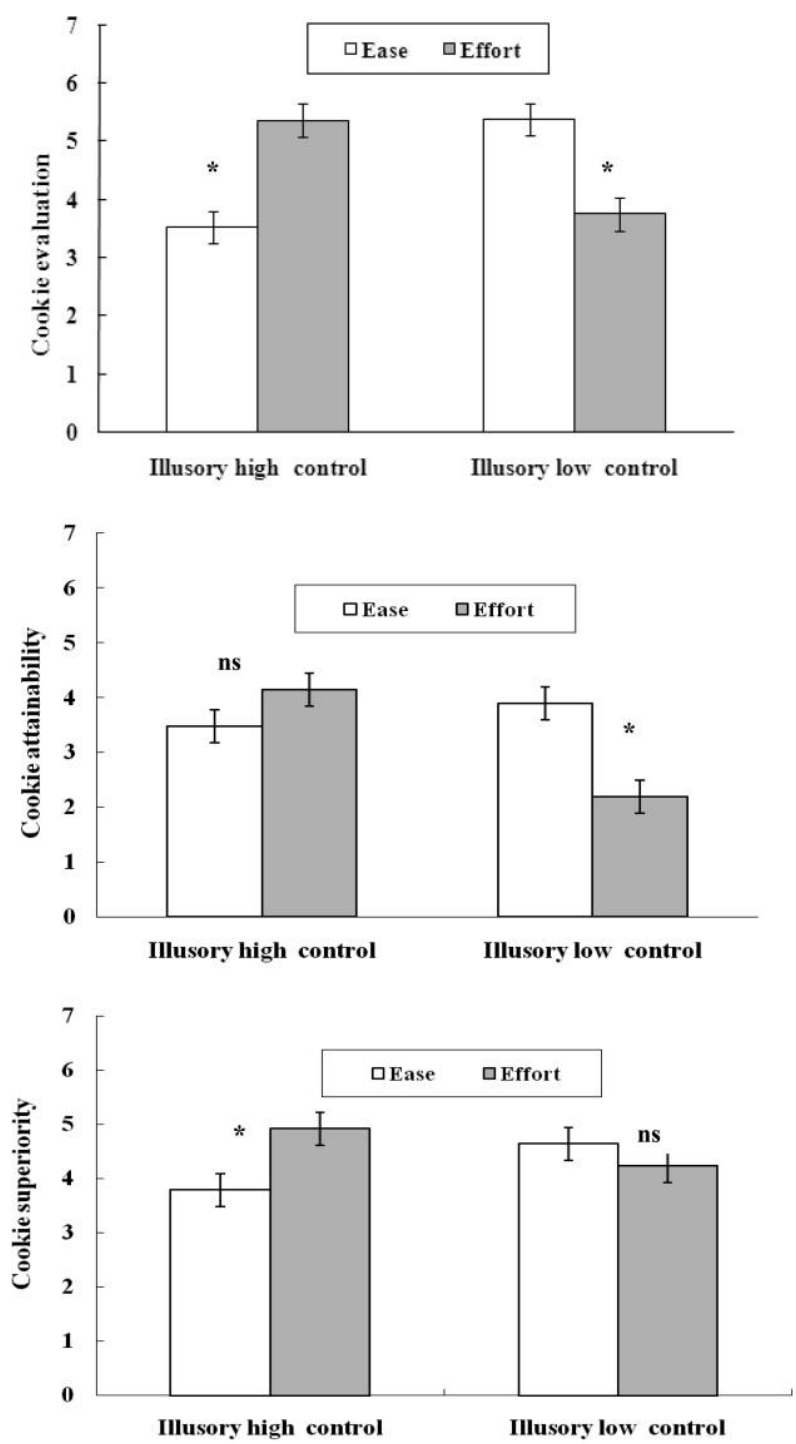

$\star p<.05$.

(where attainability and desirability are negatively correlated and a person focuses either on effort as signal of low attainability or of high desirability) because it is unclear how the meaning of effort could change but not the decision weight on either meaning. Model A implies that effort has the same direction of impact on attainability and on desirability (i.e., effort makes both attainability and desirability more positive or more negative depending on value focus).
Both models $\mathrm{B}$ and $\mathrm{C}$ allow for the possibility that attainability and superiority could be negatively correlated and value depends on the meaning of effort a person puts weight on; thus, only models B and C are consistent with a singular representation of value, and we did not find support for either model. One caveat could be that our mediation measures are better at capturing attribute level rather than decision weight and therefore we may not have observed changes in decision weight. In this respect, note that the coefficients in the regressions are reasonable indicators of decision weight. Also, any assumption that only effort but not ease is an indicator of high desirability (which is necessary for a decision weight line of argumentation; models $\mathrm{B}$ or $\mathrm{C}$ ) is at odds with numerous findings in the literature that show robust positive effects of ease on desirability (Schwarz 2004). Those studies associate ease with targets such as nonsense syllables and suggest that people directly attribute positive affect from ease to desirability of the target (Bornstein 1989; Zajonc 1968), and it is unclear what attainability of such stimuli would mean. If both ease and effort are linked positively to desirability, there must be two meanings of desirability, and the meaning used should likely depend on the lens people use to construe value itself.

It therefore follows that the only way in which an interpretation of effort could change without changing decision weights of attainability or superiority is if effort colors perceived attainability and superiority similarly either in a positive or a negative direction. Indeed, once we split the data on controllability, we find that among low-control participants, effort relates negatively to both attainability $(b=$ $-.86, \mathrm{SE}=.20)$ and to superiority $(b=-.21, \mathrm{SE}=.17$; see table 3). Among high-control participants, effort relates positively to both attainability $(b=.34, \mathrm{SE}=.22)$ and superiority $(b=.57, \mathrm{SE}=.57)$. This coloring could happen either if our measures pick up self-generated validity effects or if there are two representations of value itself (inherent vs. incentive) and the lens with which people approach value is different to begin with. We believe the data support the latter possibility. Self-generated validity seems less plausible because $(a)$ attainability and superiority are not correlated, either for low-control $(r=-.04, p>.80)$ or for highcontrol participants $(r=.05, p>.75)$; if one measure was having an impact on the other, we should have found these correlations; (b) mediators were collected in close proximity with control measures (see table 2), which did not show similar effects; and $(c)$ one could argue that self-generated validity effects would likely always necessitate a negative correlation between attainability level and superiority level, independent of the effect of effort (an assumption that fits model $\mathrm{C}$ best), but our two mediators are uncorrelated with each other $(r=.07, p>.50)$.

Also, model $\mathrm{A}$ is most compatible with a view that value might have two representations. In one representation of value, effort negatively affects both attainability and desirability, which we believe is likely to occur if an individual is tuned into inherent value, where the negative affect associated with effort makes the outcome appear less attain- 
TABLE 3

MEDIATED MODERATION: EXPERIMENT 3

\begin{tabular}{|c|c|c|c|c|c|c|c|}
\hline Equation & Effort & Focus & $\begin{array}{c}\text { Effort } x \\
\text { focus }\end{array}$ & Attainability & $\begin{array}{c}\text { Attainability } \times \\
\text { focus }\end{array}$ & Superiority & $\begin{array}{c}\text { Superiority } \times \\
\text { focus }\end{array}$ \\
\hline \multicolumn{8}{|l|}{ Overall analysis: } \\
\hline 1. Evaluation & $\begin{array}{l}.05 \\
(.14) \\
{[.38]}\end{array}$ & $\begin{array}{c}-.06 \\
(.14) \\
{[-.45]}\end{array}$ & $\begin{array}{c}.87 \\
(.14) \\
{[6.30]}\end{array}$ & & & & \\
\hline 2. Attainability & $\begin{array}{r}-.26^{+} \\
(.15) \\
-1.72]\end{array}$ & $\begin{array}{c}.38^{\star *} \\
(.15) \\
{[2.57]}\end{array}$ & $\begin{array}{r}.60 \\
(.15) \\
{[4.01]}\end{array}$ & & & & \\
\hline 3. Superiority & $\begin{array}{c}.18 \\
(.16) \\
{[1.14]}\end{array}$ & $\begin{array}{c}-.04 \\
(.16) \\
{[-.25]}\end{array}$ & $\begin{array}{r}.39^{*} \\
(.16) \\
{[2.47]}\end{array}$ & & & & \\
\hline 4. Evaluation & $\begin{array}{l}.11 \\
(.14) \\
{[.84]}\end{array}$ & $\begin{array}{c}.26 \\
(.59) \\
{[.44]}\end{array}$ & $\begin{array}{c}.49^{* *} \\
(.14) \\
{[3.60]}\end{array}$ & $\begin{array}{c}.29^{\star *} \\
(.10) \\
{[2.86]}\end{array}$ & $\begin{array}{c}-.11 \\
(.10) \\
{[-1.13]}\end{array}$ & $\begin{array}{c}.47^{\star *} \\
(.10) \\
{[4.48]}\end{array}$ & $\begin{array}{c}-.01 \\
(.10) \\
{[-.05]}\end{array}$ \\
\hline \multicolumn{8}{|c|}{ Split analysis, inherent focus (low control): } \\
\hline 1. Evaluation & $\begin{array}{c}-.81^{* *} \\
(.19) \\
{[-4.23]}\end{array}$ & & & & & & \\
\hline 2. Attainability & $\begin{array}{c}-.86^{\star *} \\
(.20) \\
{[-4.25]}\end{array}$ & & & & & & \\
\hline 3. Superiority & $\begin{array}{c}-.21 \\
(.17) \\
{[-1.25]}\end{array}$ & & & & & & \\
\hline 4. Evaluation & & & & $\begin{array}{c}.62^{\star *} \\
(.13) \\
{[4.59]}\end{array}$ & & & \\
\hline 5. Evaluation & $\begin{array}{r}-.37^{+} \\
(.21) \\
{[-1.80]}\end{array}$ & & & $\begin{array}{c}.40^{\star *} \\
(.15) \\
{[2.71]}\end{array}$ & & $\begin{array}{r}.47^{\star} \\
(.18) \\
{[2.63]}\end{array}$ & \\
\hline \multicolumn{8}{|c|}{ Split analysis, incentive focus (high control): } \\
\hline 1. Evaluation & $\begin{array}{c}.92^{* *} \\
(.19) \\
{[4.68]}\end{array}$ & & & & & & \\
\hline 2. Attainability & $\begin{array}{c}.34 \\
(.22) \\
{[1.54]}\end{array}$ & & & & & & \\
\hline 3. Superiority & $\begin{array}{r}.57^{*} \\
(.27) \\
{[2.09]}\end{array}$ & & & & & & \\
\hline 4. Evaluation & & & & & & $\begin{array}{c}.61^{\star \star} \\
(.13) \\
{[4.79]}\end{array}$ & \\
\hline 5. Evaluation & $\begin{array}{c}.60^{\star \star} \\
(.17) \\
{[3.44]}\end{array}$ & & & $\begin{array}{c}.17 \\
(.14) \\
{[1.28]}\end{array}$ & & $\begin{array}{c}.46^{\star \star} \\
(.11) \\
{[4.16]}\end{array}$ & \\
\hline
\end{tabular}

NOTE.-Standard errors are in parentheses; $t$-values are in brackets. All equations included constant terms. For overall analysis, $n=60$, Sobel $z$ attainability $=2.33, p<.01$; Sobel $z$ superiority $=2.16, p<.05$. For split analysis, inherent focus (low control), $n=31$, Sobel $z$ attainability $=2.28, p<.05$. For split analysis, incentive focus (high control), $n=29$, Sobel $z$ superiority $=1.87, p=.06$. The overall analysis reported in this table is per Muller et al. (2005). We jointly included our two mediators because attainability level and superiority level are uncorrelated $(r=.07, p>.50)$. This regression analysis gives output almost identical to simultaneous regression analysis, which runs all regressions at once. Simultaneous analysis with both mediators conducted using SAS is identical to similar analysis conducted with LISREL running all mediators and relationships at once. LISREL outputs are reported in appendix D. Running a double mediation analysis per Preacher and Hayes (2008) using INDIRECT command, in which the effect of effort $\times$ focus on evaluation simultaneously includes both mediators (attainability and superiority level) and includes effort and focus as covariates gives similar results (see app. E). Also, running this analysis with one mediator at a time does not change our overall results (see app. F).

${ }^{+} p<.10$.

${ }^{*} p<.05$.

${ }^{* *} p<.01$. 
able and less desirable (low quality, not as good). In the other representation of value, effort positively affects both attainability and desirability, which we believe is likely to occur if an individual is tuned into the incentive aspects of effort, which, in turn, would occur if effort is seen as motivationally relevant. We propose here that effort cues value by making an outcome look the best (superior; Labroo and Kim 2009a), and when faced with difficulty (e.g., effort), highly motivated people become more optimistic about their chances of getting an outcome (attainability) when they sense ongoing effort. Thus, inherent value will be associated with a lens in which attainability reflects a consideration of whether the individual can get the outcome and a consideration of whether the outcome is any good, and effort that is affectively negative will reduce both aspects of value. Incentive value will be associated with a lens in which attainability reflects an assumption that if one puts in effort one will get the outcome and the outcome is best and thus associating effort with an outcome increases both aspects of incentive value.

Additional Insights from Meditation Analysis. Interestingly, and not predicted by us, the data show that only attainability level is a mediator of value for low-control participants and that only superiority level is a mediator for high-control participants. Specifically, among low-control participants, we found a significant negative effect of effort on evaluation $(b=-0.81, \mathrm{SE}=0.19 ; t(29)=-4.23, p$ $<.01$ ), a positive effect of attainability level on evaluation $(b=0.62, \mathrm{SE}=0.13 ; t(29)=4.59, p<.01)$, a significant negative effect of effort on attainability level $(b=-0.86$, $\mathrm{SE}=0.20 ; t(29)=-4.25, p<.01)$, but a nonsignificant effect of effort on superiority level $(b=-0.21$, SE $=0.17$; $t(29)=-1.25, p>.20)$ of the cookies, which means superiority level is not a mediator for those with low control. When we included attainability level of the cookies as a covariate in the regression measuring the effect of effort on evaluation of the cookies, the effect of attainability level was significant $(b=0.40, \mathrm{SE}=0.15 ; t(27)=2.71, p<$ $.01)$, and the effect of effort on evaluation decreased in significance $(b=-0.37, \mathrm{SE}=0.21 ; t(28)=-1.80, p<$ .10 ; Sobel $z=2.28, p<.05$ ). Thus, for low-control participants, effort was interpreted as reduced level of attainability and that mediated cookie evaluation.

By contrast, for high-control participants, we found a significant positive effect of effort on evaluation $(b=0.92$, $\mathrm{SE}=0.19 ; t(27)=4.68, p<.01)$, a significant effect of superiority level on evaluation $(b=0.61, \mathrm{SE}=0.13 ; t(27)$ $=4.79, p<.01)$, a significant effect of effort on superiority level $(b=0.57, \mathrm{SE}=0.27 ; t(27)=2.09, p<.05)$, but $\mathrm{a}$ nonsignificant effect of effort on attainability level $(b=$ $0.34, \mathrm{SE}=0.22 ; t(27)=1.54, p>.13)$ of the cookies, which means that attainability level is not a mediator for those with high control. When we included superiority level as a covariate to measure the effect of effort on evaluation, the effect of superiority level was significant $(b=0.46, \mathrm{SE}$ $=0.11 ; t(25)=4.16, p<.01)$, but effort was reduced in significance $(b=0.60, \mathrm{SE}=0.17 ; t(25)=3.44, p<.01$;
Sobel $z=1.87, p=.06$ ). Thus, among high-control participants, effort was interpreted in terms of superiority level and that mediated evaluation.

This differential mediation among low-control and highcontrol participants could occur because of at least three reasons. First, it is possible that, with more statistical power, we would also observe among high-control participants a significant impact of effort on attainability and consequently on value and among low-control participants a significant impact of effort on superiority and consequently on value. Second, it is possible that our measures are not sensitive enough. Our attainability measure may not have been sensitive enough to capture entitlement among high-control participants or to capture desirability among low-control participants. Third, if the observed patterns are stable, this analysis would suggest that for high-control participants effort affects both attainability and superiority perceptions but extent of perceived superiority influences incentive value. Although perceived attainability increases because of ongoing effort, among incentive-focused (high-control) people, value is mediated by the extent to which effort makes the outcome look superior. Instead, among low-control participants ease makes outcome look more attainable and more desirable, but value depends on the extent to which the outcome can be attained. This latter possibility is somewhat at odds with research showing that ease has a direct effect on value via desirability (Schwarz 2004), but it is possible that our measure did not adequately capture desirability. These aspects of the data offer rich and new theoretical insights and possibilities for future research. In experiment 4 , we test for robustness of these patterns in the data using another context for investigation.

These findings should not be interpreted to say that focus will never change decision weight. One reason we did not find change in decision weight having an impact on value may be because in our outcome, across conditions, information about attainability and superiority was constant and identical (other than the meaning of effort). Although only a conjecture, we believe it is possible that, if we had choice between two options that differed on attainability versus superiority, then final choice would include changes in decision weight. Also, if we ignore our effort manipulation (e.g., presume that perceived effort is person specific and is picked up in the rating of attainability and of superiority) and create a net superiority index by subtracting the score on level of attainability from that on the level of superiority, and model value as a function of controllability, net perceived superiority, and their interaction, we find a significant effect of controllability $\times$ net superiority index on evaluation $(b=0.26, \mathrm{SE}=0.10 ; t(56)=2.60, p=.01)$. This finding is compatible with views in past research suggesting that value depends on whether people weight attainability or superiority more and on the inference they make specific to the aspect they weight, the other meaning being assigned a zero weight (e.g., Wilkie and Pessemier 1973). The reality, of course, appears to be more nuanced, as just described, and it appears that some past findings that proposed an effect 
on evaluation because of a change in decision weight may actually have alternatively or additionally been observing the effect of an interpretation of decision-evoked feelings. Future researchers should include direct measures of weight and level in the same study, or manipulate inherent value versus incentive value directly, and should measure each item with different participants to ensure against self-generated validity effects.

\section{EXPERIMENT 4: EXERTING EFFORT TO MAKE A REAL DONATION}

Experiment 4 extends the findings from experiments 1-3 in several ways. First, experiments 1-3 employed hedonic products whose consumption might need to be justified with effort (Kivetz and Simonson 2002), and it is possible, though unlikely, that people with incentive focus (high control) somehow need to justify guilty consumption more. To ensure generality of our findings, we employ a donation task in experiment 4 that does not require any justification. Second, we measure actual behavior (real donation to charity) to observe real actions of consumers. Third, we test the robustness of our mediation. Researchers have argued that the error terms of a dependent variable and of a mediator could always be correlated because of a third causal factor (Bullock, Green, and $\mathrm{Ha}$ 2010). To ensure against this possibility, researchers should include a condition that turns off the mediator so that the mediating effect is no longer observed on the dependent variable. Thus, we included a condition in which we turn off inference by directing participants' attention to the true source of (noninstrumental) effort. We expect that, when participants are aware that effort is not a reflection of superiority, they will no longer interpret effort as a signal of outcome superiority and will unbias their evaluations (Schwarz 2004). Experiment 4 thus used a 2 (value focus: inherent vs. incentive) $\times 3$ (real noninstrumental effort: low, high, or high + source aware) between-subjects design, with actual money donated to charity as a dependent variable.

\section{Method}

Seventy-four undergraduate students participated for compensation. Upon arrival at the lab, each participant signed a consent form, learned that he or she would participate in two studies, and was then seated at a desk in an adjacent room. A 3 inch $\times 2$ inch board comprising information about a charity (http://www.kidsindanger.org) sat on the desk. This charity is real, and the materials are incredibly sad; they describe young children who died due to defective consumer products, including the story of Baby Danny, whose crib crushed him at his day care facility after he attempted to stand up. As the cost of attending to these materials is high (Fishbach and Labroo 2007), justifying a donation to the charity is unlikely. A metal donation box was attached to the board.

We used two replicates for the focus manipulation. We assigned each participant to only one of the two manipulations, and within the manipulation, we assigned each to either the inherent or the incentive value focus condition.
Incentive-focus participants were either told that they were among the first to participate in the study (suggesting that they could set the patterns for and influence the rest of the study and might therefore wish to focus on the best they could do [Langer 1975]; an inference consumers might freely make is that they are among the first or last to enter a store, try a product, or support a cause) or, in an alternative manipulation, were asked to list three ways in which they could help children (again something marketers can manipulate in their advertising, and presumably people list three reasons easily and they list the best ways to do so first). Inherent-value-focus (low-control) participants were either told they were among the last to participate in the study, suggesting that most of the study had been completed and they could no longer influence it (Langer 1975); or, in an alternative manipulation, they were asked to list seven ways in which they could help children. We based this second manipulation on past literature (Schwarz 2004) that demonstrates that, even though seven ways are objectively more ways than three to be influential, generating more ways is difficult, which reduces perceived control, which, in turn, shifts value focus to inherent value. A pretest $(n=30)$ confirmed that being among the first rather than the last to participate induced incentive focus (My focus is on . . . ; $0=$ whether I would like to make a difference in life of children in danger, $1=$ donating only to the best charity; $\left.M_{\text {first }}=71.4 \%, M_{\text {last }}=21.4 \% ; \chi^{2}(1)=7.04, p<.01\right)$. Another pretest $(n=30)$ confirmed that listing three (vs. seven) ways induced incentive focus $\left(M_{3}=80.0 \%, M_{7}=\right.$ $\left.33.3 \% ; \chi^{2}(1)=6.65, p<.01\right)$.

We manipulated anticipated effort with physical distance. Before each participant arrived in the room, depending on the effort condition to which the participant was assigned, we placed the box either close to ( 2 feet away) or farther away from (4 feet away) the participant. Participants in the distant condition would need to stretch out their arms to put money in the box, exerting real effort; those in the near condition could easily make a donation if they wanted.

Procedure. After participants were seated, they received an answer booklet in which to complete the survey. In it, participants responded to several questions, including demographic variables and whether being good and kind was important to them (yes/no response; all participants, regardless of value focus [control] replication type [item generation vs. feedback] or focus condition [inherent vs. incentive focus], answered yes to this question). Participants for whom we manipulated focus through the item-generation task next listed three (incentive-focus condition) or seven (inherent-focus condition) ways in which they could help people. Participants for whom we manipulated focus through the feedback manipulation were simply thanked after they had responded to the yes/no question, for either being among the first (incentive) or last (inherent) to participate in our study. The two replications of focus yielded similar patterns of results, and they were collapsed to form a single incentive (inherent) focus condition.

Once participants completed the survey, experimenters 
told them the study was over and compensated them. Experimenters explained that the participants would need to wait 5 minutes for the next study, which was in an adjacent room. We invited them, in the meantime, to look over materials publicizing a local charity, to answer a few questions for which we had agreed to get responses if possible, and to make an anonymous donation if they wished. All participants agreed to look over the materials and answer the questions while they waited alone in the room. The room was small, clean, and private, and it contained only the desk, chair, and donation materials, as well as no two-way mirrors in order to ensure the participant recognized the donation, if made, would be anonymous. We manipulated illusory control (focus) by the first task and manipulated effort by varying the distance of the donation box from the participant (near or far). At this time, to make participants in the effort + source condition aware of the true source of effort, experimenters explained that "by the way, we placed the box somewhat far from you."

In the booklet, participants were first asked to make a donation if they wished to do so. After this invitation, participants provided evaluations of the charity, perceived attainability of impact, perceived superiority of the charity, and all of the control measures included in experiment 3 . For brevity and because the results perfectly replicate those of experiment 3 , we only discuss the real donation measure but report all evaluations means and mediation analyses in tables $1-3$

\section{Results and Discussion}

We first tested whether donation rate was affected by focus (controllability) and donation effort (see table 4). A binary logistic regression on a score that coded for whether a participant made a donation $(0=$ no, $1=$ yes $)$ with value focus (inherent, incentive), effort (low, high), and their interaction revealed only a significant effect of interaction $(b$ $=0.80, \mathrm{SE}=0.37$; Wald $=4.72, p<.05)$. Among incentive-focused (high-control) participants, the donation rate was higher when effort was high $\left(M_{\text {close }}=54 \%, M_{\text {far }}=\right.$ $\left.92 \% ; \chi^{2}(1)=4.88, p<.05\right)$; when alerted to the source of effort (distance), the donation rate decreased to become no different from that of participants in the close condition $\left(M_{\text {far }+ \text { source }}=58 \%, p>.80\right)$. Similar effects did not emerge for inherent-value (low-control) participants, though donation rates were in the direction that one might expect $\left(M_{\text {close }}\right.$ $=77 \%, M_{\mathrm{far}}=58 \% ; \chi^{2}(1)=.99, p<.30 ; M_{\mathrm{far}+\text { source }}=$ $73 \%, p>.80)$.

We next tested whether donation amount increased among those who decided to make a donation $(n=51)$. A 2 (focus) $\times 3$ (effort) between-subjects ANOVA on amount donated only revealed a significant interaction $(F(2,45)=6.66, p<.01)$. As predicted, in the inherent value (low-control) condition, participants donated less money when the box was far away $\left(M_{\text {close }}=77.50\right.$ cents, $M_{\text {far }}=42.86$ cents, $\left.t(45)=2.45, p<.01\right)$; when alerted to the source of effort (distance), their donation amount increased to become no different from that of participants in the easy (close) condition $\left(M_{\text {far }+ \text { source }}=65.63\right.$ cents, $t$ $<1)$. This measure, in conjunction with the donation rate measure, suggests that making a donation by itself is effortful to inherent-value-focused (low-control) participants, but if they are willing to make a donation, they donate more when it is easy to do so. More interestingly, in the incentive focus (high-control) condition, participants donated more when the donation box was far away rather than close $\left(M_{\text {close }}\right.$ $=46.43, M_{\text {far }}=83.33$ cents; $\left.t(45)=2.71, p<.01\right)$, but when alerted to the source of effort (distance), their donation amounts became no different from the amounts donated in the easy (close) condition $\left(M_{\mathrm{far}+\text { source }}=67.86\right.$ cents; $t(45)=$ $1.39, p>$.17). Thus, incentive-focused (high-control) participants were both more willing to make a donation when making a donation was effortful, and once they decided to make a donation, they donated more money when it was effortful to do so. When effort no longer served as information pertaining to the superiority of the charity, donation rate and donation amount reduced to become no different from the rate and amount when donation was easy. Importantly, we observed mediated moderation effects similar to those in experiment 3 in this experiment (see table 3 for data). Also, in the condition where we manipulated the mediator by making people source aware of effort, the effect turned off, thus suggesting, in line with Bullock et al. (2010), that the effects indeed are because of our mediated processes.

The findings of this experiment are noteworthy for several reasons. First, unlike experiments 1-3, which employed hedonic target products whose consumption individuals might feel the need to justify, this study used donation to charity as a dependent variable. By using this variable, we ruled out the notion that incentive-focused people somehow feel a need to justify their actions and choose to exert effort because it can serve as a justification for consumption. Second, we measured actual behavior (donation to charity) in addition to attitudes toward the target, and we used objective rather than subjective effort. Thus, the study importantly demonstrated for a first time that focus has real implications for people's behaviors and that those whose focus is on incentive value engage in more objective effort because they perceive outcomes to be superior. But effort does not guarantee a superior outcome in reality, and certainly in our studies it did not. The outcome that an investment of more effort ensured was either identical to or inferior to what ease ensured. Thus, these findings suggest that when people's focus is on getting the best (experiment 1), as it might be if they see themselves as deserving and in control of their outcomes (experiments $2 \mathrm{~A}$ and $2 \mathrm{~B}$ ), or when something in the environment makes them feel in control and so turns their focus on the best (experiments 3 and 4), they end up unnecessarily overvaluing effortful outcomes. Third, by including a condition in which we directed participants' attention to the source of effort, we found that when effort does not reflect value, people correct their actions. Importantly, source awareness increased donation among 
TABLE 4

MEDIATED MODERATION: EXPERIMENT 4

\begin{tabular}{|c|c|c|c|c|c|c|c|}
\hline Equation & Effort & Focus & $\begin{array}{l}\text { Effort } x \\
\text { focus }\end{array}$ & Attainability & $\begin{array}{l}\text { Attainability } \times \\
\text { focus }\end{array}$ & Superiority & $\begin{array}{l}\text { Superiority } \times \\
\text { focus }\end{array}$ \\
\hline \multicolumn{8}{|l|}{ Overall analysis: } \\
\hline 1. Donation & $\begin{array}{l}.10 \\
(.03) \\
{[.27]}\end{array}$ & $\begin{array}{l}.10 \\
(.03) \\
{[.28]}\end{array}$ & $\begin{array}{c}.13^{\star *} \\
(.03) \\
{[3.76]}\end{array}$ & & & & \\
\hline 2. Attainability & $\begin{array}{r}-.33 \\
(.21) \\
{[-1.61]}\end{array}$ & $\begin{array}{r}.43^{*} \\
(.21) \\
{[2.11]}\end{array}$ & $\begin{array}{r}.45^{*} \\
(.21) \\
{[2.20]}\end{array}$ & & & & \\
\hline 3. Superiority & $\begin{array}{r}.13 \\
(.12) \\
{[1.06]}\end{array}$ & $\begin{array}{r}.27^{*} \\
(.12) \\
{[2.24]}\end{array}$ & $\begin{array}{c}.37^{* *} \\
(.11 \\
{[3.02]}\end{array}$ & & & & \\
\hline 4. Donation & $\begin{array}{l}.01 \\
(.04) \\
{[.01]}\end{array}$ & $\begin{array}{r}-.35 \\
(.26) \\
{[-1.33]}\end{array}$ & $\begin{array}{l}.01 \\
(.04) \\
{[.21]}\end{array}$ & $\begin{array}{c}.16^{\star *} \\
(.04) \\
{[4.08]}\end{array}$ & $\begin{array}{c}-.01 \\
(.03) \\
{[-.08]}\end{array}$ & $\begin{array}{r}.10^{+} \\
(.05) \\
{[1.99]}\end{array}$ & $\begin{array}{c}.06 \\
(.05) \\
{[1.16]}\end{array}$ \\
\hline \multicolumn{8}{|c|}{ Split analysis, inherent focus: } \\
\hline 1. Donation & $\begin{array}{r}-.13^{\star} \\
(.05) \\
{[-2.51]}\end{array}$ & & & & & & \\
\hline 2. Attainability & $\begin{array}{c}-.78^{\star *} \\
(.25) \\
{[-2.95]}\end{array}$ & & & & & & \\
\hline 3. Superiority & $\begin{array}{c}-.24 \\
(.23) \\
{[-1.04]}\end{array}$ & & & & & & \\
\hline 4. Donation & & & & $\begin{array}{c}.12^{\star *} \\
(.03) \\
{[3.68]}\end{array}$ & & & \\
\hline 5. Donation & $\begin{array}{c}-.03 \\
(.06) \\
{[-.44]}\end{array}$ & & & $\begin{array}{r}.12^{+} \\
(.06) \\
{[1.95]}\end{array}$ & & $\begin{array}{l}.01 \\
(.06) \\
{[.06]}\end{array}$ & \\
\hline \multicolumn{8}{|c|}{ Split analysis, incentive focus: } \\
\hline 1. Donation & $\begin{array}{c}.14^{\star *} \\
(.05) \\
{[2.82]}\end{array}$ & & & & & & \\
\hline 2. Attainability & $\begin{array}{l}.12 \\
(.31) \\
{[.39]}\end{array}$ & & & & & & \\
\hline 3. Superiority & $\begin{array}{c}.50^{\star *} \\
(.11) \\
{[4.68]}\end{array}$ & & & & & & \\
\hline 4. Donation & & & & & & $\begin{array}{c}.25 \\
(.07) \\
{[3.43]^{\star *}}\end{array}$ & \\
\hline 5. Donation & $\begin{array}{l}.02 \\
(.07) \\
{[.22]}\end{array}$ & & & $\begin{array}{c}.13^{* *} \\
(.04) \\
{[3.17]}\end{array}$ & & $\begin{array}{r}.17^{+} \\
(.09) \\
{[1.85]}\end{array}$ & \\
\hline
\end{tabular}

NOTE.-Standard errors are in parentheses; $t$-values are in brackets. For overall analysis, $n=36$ (excluding "source aware" participants and conditional on making a donation); Sobel $z$ attainability $=1.94, p<.05$; Sobel $z$ superiority $=1.72, p=.08$. For split analysis, inherent focus, $n=17$, Sobel $z$ attainability $=1.69, p=.09$. For split analysis, incentive focus, $n=19$, Sobel $z$ superiority $=1.72, p=.08$. All equations included constant terms.

${ }^{+} p<.10$.
${ }^{*} p<.05$.

${ }^{* \star} p<.01$.

low-control participants; thus, it was not a cue to ignore effort.

\section{GENERAL DISCUSSION}

This article specifies when and why people infer value from effort, even noninstrumental effort, and when and why ease conveys value. Ample research had shown that, all things being equal, people value easy rather than effortful choices (Dhar 1997; Iyengar and Lepper 2000; Simonson 1989). Ease is associated with low cost and thus high attainability of an outcome (Iyengar and Lepper 2000; Payne et al. 1993; Whittlesea 1993). It is also associated with perceived familiarity and high desirability of an outcome (Bornstein 1989; Lee and Labroo 2004; Schwarz 2004; Winkielman and Cacioppo 2001). Other research, however, has shown 
that associating effort rather than ease with a choice can increase preference, for instance, when people are pursuing important goals (Labroo and Kim 2009a), when they think they are at a relative advantage compared to others to get an outcome (Kivetz and Simonson 2003), when they are looking for special occasion products (Pocheptsova et al. 2011), and when they are trying to assess whether a promotional offer is really among the best they can get (Lo et al. 2007). In these situations, effort appeared to increase perceived desirability of an outcome and the exertion of effort suggested that the outcome must now be attainable. Taken together, these findings thus suggested that ease can convey value by increasing perceived attainability and perceived desirability of an outcome, but effort too can convey value by increasing perceived attainability and perceived desirability.

To reconcile these mixed findings, we proposed that, although value is always a positive function of judged outcome attainability and of desirability, value itself may have two representations and the impact of effort on value depends on the type of value being considered. In particular, recent findings suggest a distinction between inherent (liking) and incentive (wanting) value and that general or inherent value increases with positive affect whereas incentive value has more of a motivational basis to it and increases with negative affect (Berridge 1999; Dai et al. 2008; Winkielman and Berridge 2003). For the most part, liking and wanting are positively correlated, because liking usually is a precursor to wanting (Dai et al. 2010), but when incentive value is highlighted, the two may become dissociated (Litt et al. 2010). We proposed that, if in general positive affect increases liking, as proposed by other research (Lee and Labroo 2004; Reber et al. 1998; Schwarz 2004; Wänke et al. 1997; Winkielman and Cacioppo 2001), then, when people are considering the inherent value of an outcome, associating effort, which is affectively negative (Botvinick et al. 2009; Luce et al. 1999; Thompson et al. 2009; Payne et al. 1993), will reduce value by making the outcome appear less attainable and less desirable. In contrast, if incentive value is motivationally based (Dai et al. 2010), then when people are considering whether they want an outcome, associating effort with the outcome will highlight the motivational meaning of effort. Effort usually is a positive cue pertaining to motivation: effort makes outcomes appear more desirable to motivated individuals because motivated people usually associate effort with the best outcomes (Labroo and Kim 2009a) and motivated people expect to get outcomes they put effort into trying to attain and become optimistic about their chances of attaining those outcomes (Taylor and Brown 1988). Therefore, among people considering incentive value and whether it is best, associating effort to an outcome will make it seem more attainable and more desirable.

Across five studies, we provided evidence in support of this framework. We directly manipulated people's focus on incentive value (ensuring the best outcomes; experiment 1), indirectly manipulated focus through people's perceived control over the best outcomes (experiments 3 and 4), or we measured people's chronic focus on getting the best outcomes (experiments $2 \mathrm{~A}$ and $2 \mathrm{~B}$ ). Regardless of whether framing, situational cues, or chronic focus were used to highlight incentive value (wanting the best), we found that incentive-focused people construed effort in line with their value focus as a positive cue pertaining to outcome attainability and desirability. We obtained our effects with subtle manipulations in the form of an opportunity to choose one's number on a lottery ticket or to infer that one is the first to set a trend-manipulations that mimic real-world situations but provide clean tests of theory. Thus, an additional contribution of this research is in showing that outcome controllability may be a valid manipulation of focus on incentive value.

Across the studies, we also manipulated effort. For subjective effort, we used a blurry rather than clear picture of a potential date (experiment 2A), a pastel rather than bright product mock-up (experiment $2 \mathrm{~B}$ ), or a perceptual illusion of distance in the shelving of a product (experiment 3). For objective effort, we used store location (experiment 1) or whether the respondent would have to stretch to make a donation he was contemplating (experiment 4). Regardless of our manipulation of focus and effort, the effects were robust and consistent. Future research should consider other ways in which objective and subjective effort might be similar or different. But an important contribution of this article is in showing that objective and subjective effort are similarly open to interpretation and their influence on perceived value occurs in a similar manner via the lens people adopt to construe value. Although some research has shown that the impact of subjective effort on value depends on how that effort is interpreted (Labroo and Kim 2009a, 2009b), objective effort is a much stronger test of pervasiveness of the phenomenon.

The most important contribution of this research is in showing process evidence that distinguished between two key possibilities pertaining to how effort might have an impact on value: by changing weights on different aspects of value (attainability and desirability) or based on a different framing of value itself (inherent vs. incentive). The former hypothesis, which was not favored by us, was that effort is a negative cue pertaining to attainability (effortful outcomes are costly to attain) but a positive cue pertaining to desirability (more important outcomes require effort and thus are more desirable). Value is always a function of attainability and of desirability, and effort is a simultaneous cue that makes an outcome less attainable but more desirable. Thus, depending on the weight a person puts on attainability versus desirability, effort can have a negative or positive impact on value. We did not agree with this hypothesis because there is extensive evidence showing that effort is also a positive cue pertaining to attainability (Taylor and Brown 1988) and a negative cue pertaining to desirability (Bornstein 1989; Lee and Labroo 2004; Schwarz 2004; Winkielman and Cacioppo 2001). Thus, for us, the resolution was in recognizing that value itself must have two represen- 
tations, one in which the negative affect associated with effort conveys low attainability and low desirability of an outcome, the other in which the negative affect associated with effort implies motivational relevance and conveys high attainability and high desirability of an outcome. Process measures (mediated moderation; experiments 3 and 4) provided support toward this latter premise: highlighting incentive value via a controllability manipulation resulted in a positive (though nonsignificant) impact of effort on attainability and a significant impact on superiority. Evaluations of attainability and superiority were not correlated (and it did not matter whether the mediators were measured before or after the dependent variable), nor did we find any movements in control measures we collected as a guard against possible alternative accounts, suggesting that our effects are unlikely to be accounted for by self-generated validity effects.

\section{Alternative Accounts}

Following Winer (1971), a meta-analysis across our five studies confirmed among the inherent-value focused a preference for outcomes associated with ease $(z=5.95, p<$ .01 ), but among the incentive focused a preference for outcomes associated with effort $(z=6.47, p<.01)$, showing that effort alone neither conveys cost or value. Rather, the decision context that surrounds anticipated effort, and the inferences people make, determine how effort affects the value of an outcome. Accounts ranging from a desire to justify one's exerted effort, a need to reduce cognitive dissonance for having exerted effort, or the tendency to mistakenly fail to recognize effort as a sunk cost are not viable explanations for our data. That literature is very clear that justification effects only arise postchoice or after having exerted effort. For instance, students think that they deserve better grades because they studied for an exam (effort heuristic; Kruger et al. 2004), consumers evaluate a service based on waiting time (Yeung and Soman 2007), and people are more likely to go to the game even if their favorite team failed to qualify once they buy the ticket (sunk cost effect). In contrast to those well-documented effects, our research shows that (some) people infer value from effort even before exerting it and that subjective effort is similar to anticipated objective effort. We observed our effects with planned real effort (experiment 1), prior to engaging in real effort (experiment 4), and with subjective effort (experiments $3,2 \mathrm{~A}$, and $2 \mathrm{~B}$ ). Also, altering people's attention to effort led to correction effects; in the case of justification effects, one could argue that attention to effort should have further increased justification and value.

Also, in experiment $2 \mathrm{~A}$, evaluation of the woman but not the man was affected based on effort and controllability, which is in line with our predictions that only people (men) who see incentive value in an outcome (woman) will infer added value of the outcome from effort. According to a sunk cost interpretation, if anything, effort should have similarly increased both evaluations. Additionally, we found that effort increased outcome desirability and attainability only under incentive focus, in line with our theorizing, a moderated effect not shown in any research on dissonance or sunk cost. Thus, our contribution also is not in simply showing that whereas effort heuristic says that the harder people work toward getting an outcome, the more they value the outcome, we show that even before people work toward an outcome, they sometimes prefer an outcome involving more effort. Instead, we show that anticipated effort can sometimes be a signal of positive value. And we showed a broad array of situations (social, consumer, planning, chronic, and situational, with real or subjective effort) that result in value from effort.

Involvement also is unlikely to account for our findings. In all studies, we measured involvement-target variables did show movement; this one did not. Also, from a theoretical perspective, involvement and outcome controllability are likely to be orthogonal (affect can increase elaboration, just as motivation can), and it is not clear a priori whether high or low controllability would increase involvement or what predictions might follow were controllability to affect involvement. Put differently, people could be highly involved or not at all involved when considering inherent value or when considering incentive value. In any case, across most of our studies, effort associated with the outcome, regardless of whether it was objective or subjective, made the outcome normatively inferior. For instance, a blurry picture or a product mock-up is worse than a clear one, and a distant donation box or store is inferior to one nearby. High-controllability people preferred such outcomes; if they were highly involved, at a minimum they should have found the two outcomes equally desirable. Also, if low control increased involvement, such participants should not have made evaluations based on their subjective feelings, preferring subjectively easy outcomes to effortful ones, and if they were highly involved, it is unclear why they should correct their evaluations when directed to the source of effort (experiment 4). However, future research might investigate whether involvement moderates our effects; we predict stronger effects among high-involvement participants such that those who feel high control prefer effortful products and those who feel low control prefer easy-to-get products but only if they are engaged in the choice process. Indeed, such a proposition is consistent with findings by Labroo et al. (2009) showing that people consider information more important when they associate the information with effort (vs. ease) to understand but that those effects especially arise among high-involvement respondents who associate effort with importance more strongly.

Construal level theory (CLT) also does not provide a reasonable alternative account for our data. Even though CLT can predict that abstract construal will increase focus on desirability, past research does not support the view that effort rather than ease will always increase desirability (Bornstein 1989; Schwarz 2004). Our argument is that effort will convey desirability only when people are focused on the best (incentive value), and we make this prediction based on selfperception theory (Bem 1972). It is possible that because an abstract construal is known to increase goal accessibility (Fujita et al. 2006) and goal accessibility induces an incentive 
focus (Labroo and Kim 2009a), CLT would be able to predict our effects. But for such an effect, CLT would have to suggest that value is construed differently, in incentive terms, by those with abstract construal and inherent terms by those with concrete construal. Existing research on CLT to date instead suggests that construal results in differential weights on attainability and desirability but that value always is singular and represented as inherent value. But our framework would additionally suggest that if people with a concrete construal become incentive focused, effort is likely to increase value for them as well (or instead). In sum, we would suggest that either an abstract or a concrete construal can increase the interpretation of effort as a signal of value. In fact, our model implies that any factor, such as incremental theory (a belief that effort results in self improvement; Miele and Molden 2010), optimizer mind-set, or power (a general belief of influence over other people or situations), that corresponds with an incentive focus will result in positive evaluations of outcomes associated with anticipated effort, but because the positive evaluations will arise from the self-perception process proposed by our model, anything that shifts focus of these consumers away from incentive value will also reverse the effects of effort on evaluation. Future research should test our model in these contexts.

\section{Implications and Future Research}

Our findings also build on Labroo and Kim (2009a). Labroo and Kim (2009a) focused only on goal pursuit and only on subjective effort. Instead, here we provide a richer framework that applies to $(a)$ all kinds of effort, including real and planned effort, $(b)$ all kinds of situations, social as well as consumer, and, most importantly, (c) specifies the process by suggesting that representation of value underlies a positive or negative impact of effort on evaluation. In doing so, we integrate the minority of studies showing effort preference with the majority on effort avoidance to speak to when and why either effect will hold.

One limitation of the current research is that it does not distinguish clearly whether our manipulation of inherent value and incentive value changes a consumer's frame of reference (e.g., considering whether the outcome is good or bad based on its attributes vs. considering whether the outcome is best against other outcomes on a particular dimension) or results in a differential reliance on affect versus motivation. We suggest the former and that a positive affect increases inherent value but a negative affect increases incentive value. Thus, affect influences both incentive value and inherent value but in different ways because different meaning is assigned to the affect. But it is possible that inherent value is purely affective and that incentive value is purely motivational. In our studies, people considering inherent value made an affective decision but people considering incentive value relied on motivation. But this view would imply that in general decisions are affective (our inherent value condition often was similar to what a baseline would look like) but that occasionally people can be guided into using motivation, which seems unlikely. Instead, it appears more plausible that in general people consider goodness of an alternative based on its attributes (inherent value) and that a positive affect increases such value but that whether that alternative is best suited against other alternatives (incentive value) and in such situations negative affect conveys motivational relevance. It is also possible that highlighting motivation could spontaneously change frame of reference to considering the best (against other alternatives on a certain dimension), whereas highlighting affect could spontaneously change frame of reference to considering how good an outcome is (on its own attributes). These ideas should be tested systematically. Future research should manipulate liking and wanting in different ways by directly evoking affective versus motivational concerns and manipulate inherent and incentive frame of reference by evoking attribute- or alternative-based comparison.

Also important are the marketing, practical, and policy implications. We show that small but real aspects of our consumption environment-perceived shopping skill, choosing one's own lottery number, information framing, inferring one's actions will set a trend, or deciding one is in a position to make an impact-all result in seeing value from effort. Policy-wise, workaholics who claim a genuine passion for work abound, and they may be the ones likely to construe value in incentive terms. Our work cautions that such individuals might not only be complicating their lives to end up with objectively worse outcomes but that their incessant quest of effort could result in dire consequences, from health problems to regret that one missed out on life's simpler pleasures. Future research should also extend our framework to other domains. For example, other factors, such as mixed emotions or ambiguity in advertising, that correlate with negative feelings are mostly considered to exert a negative influence on evaluations, but our research suggests that if our effects are general to apply to negative feelings, then in situations where people want the best outcomes, the use of mixed emotion or ambiguity may exert a favorable impact on evaluation and choice. All of these premises await future research. 


\section{APPENDIX A \\ STIMULUS MATERIALS}

FIGURE A1

SCENARIOS USED (EXPERIMENT 1)

Your close friend Pat's $21^{\text {st }}$ birthday is coming up. You and Pat were very close growing up, but over the last few months Pat has been working overseas for the marines and you are unlikely to see or talk to Pat soon. Marine bases allow alcohol on special occasions and thankfully Pats superiors have promised to ship your present to Pat. You want to surprise Pat with an exceptional bottle of wine, simply the best one you can find for your closest buddy. After reading the wine spectator magazine and talking with a few connoisseurs, you settle on a particular wine label.

\begin{tabular}{|l|l|}
\hline EXCELENCE & $\begin{array}{l}\text { 1988 Piedmont Barolo. Noble and generous, glory of old Piedmont, a wine suitable } \\
\text { for long aging, Barolo is the absolute master of the table. It conquers the palate with } \\
\text { the conviction of strength, harmony and fullness and holds its sway at length. Barolo } \\
\text { Marcenasco has ancient origins. There are historical documents from the "Rigestum } \\
\text { Comunis Albe" that bear witness to the cultivation of the Nebbiolo vine in the } \\
\text { "Marcenascum" area already back in the 12th Century. Barolo Marcenasco is } \\
\text { smooth, balanced, elegant and faithfully reflects the typical characteristics of the La } \\
\text { Morra sub zone. Color: Intense garnet red. A bouquet with traces of licorice and } \\
\text { tobacco. Full flavored, full-bodied and elegant. } \\
\text { 96 Points Wine Spectator. }\end{array}$ \\
\hline
\end{tabular}

You are planning on going to the store [are wondering whether the wine is worthy of going to the store] to speak with the salespeople before you buy it. To your surprise, an internet search reveals that the bottle is available in only one store, and that store happens to be just down the road [half way across town] from where you stay.

NOTE._Color version available as an online enhancement. 


\section{Flirting Superiority Scale}

(Kim and Labroo)

\section{General Self-Esteem Scale \\ (based on Rosenberg 1965)}

- I have a number of good qualities

- I am able to do things well

- I feel I have much to be proud of

- I take a positive attitude toward myself

- On the whole, I am satisfied with myself

- I am not shy initiating conversation with a woman I like

- I think I'm good at talking with women.

- I feel confident that I make a good first impression with women

- I'm good at flirting.

\section{General Communication Scale} (based on Duran 1992)

- I'm good at presenting a talk to a group of people

- I'm good at talking in a small group of people

- I'm good at talking with a person

- I'm good at talking in a large meeting of people

\section{Shopping Superiority Scale \\ (Kim and Labroo)}

- I usually am in control of my shopping decision

- I usually don't regret about what I bought

- I'm good at dealing with sales people 
FIGURE A3

PICTURES OF WOMAN (EXPERIMENT 2A) AND PRODUCT MOCK-UP (EXPERIMENT 2B)
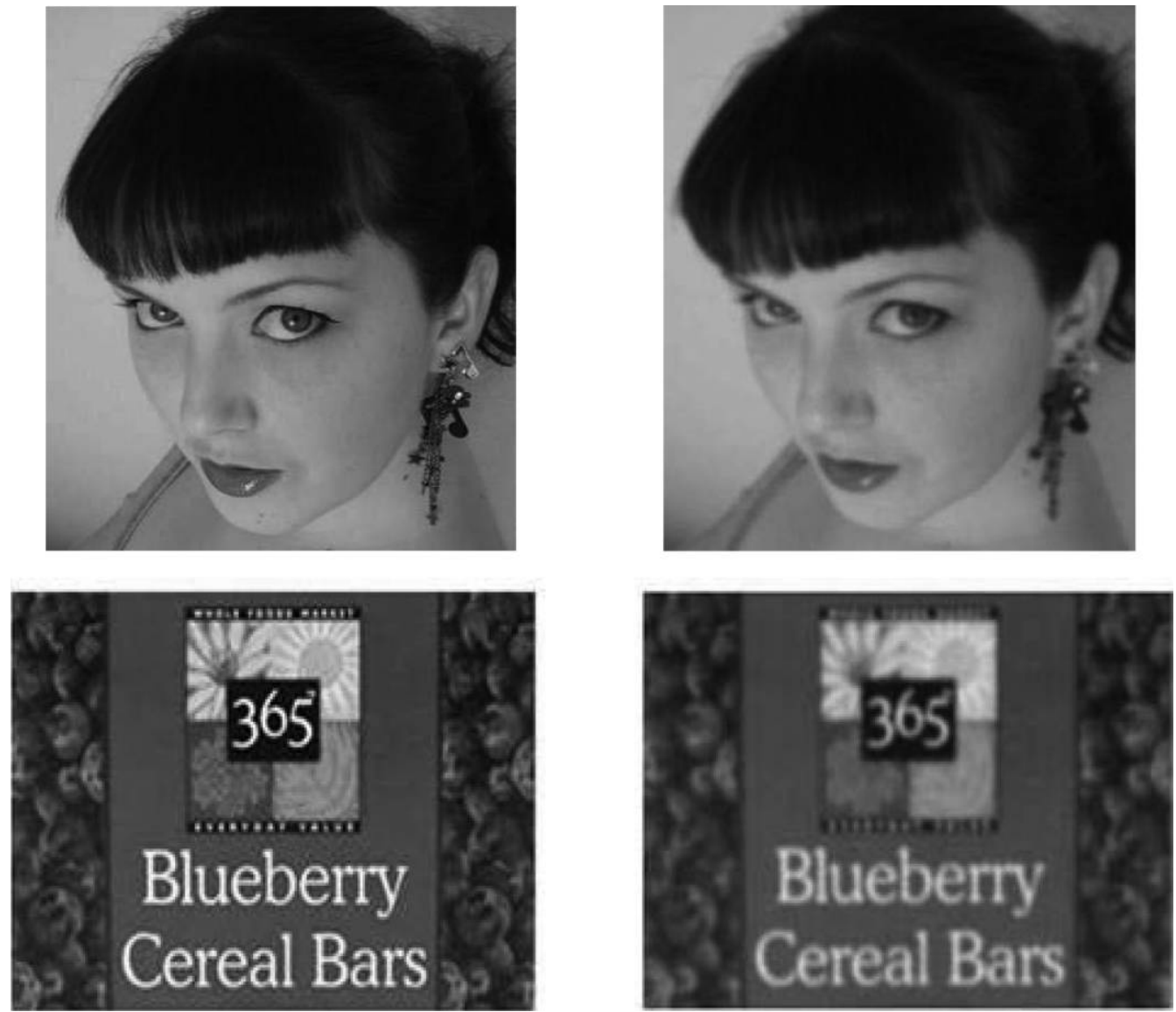

NOTE.-In each panel, the left picture is clear and the right picture is blurry. Color version available as an online enhancement. 
APPENDIX B

FIGURE B1

MODEL TESTING MEDIATED MODERATION EFFECT OF EFFORT ON EVALUATION (EXPERIMENT 1)

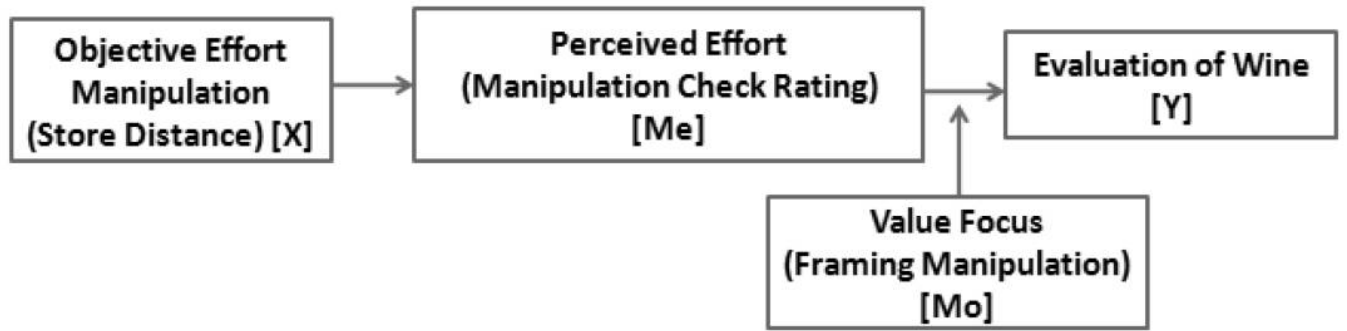

Note: Conditions for this model to hold include:

1. $\mathrm{Y}=\mathrm{b} 40+\mathrm{b} 41 \mathrm{X}+\mathrm{b} 42 \mathrm{Mo}+\mathrm{b} 43 \mathrm{XMo}$

2. $\mathrm{Me}=\mathrm{b} 50+\mathrm{b} 51 \mathrm{X}+\mathrm{b} 52 \mathrm{Mo}+\mathrm{b} 53 \mathrm{XMo}$

3. $\mathrm{Y}=\mathrm{b} 60+\mathrm{b} 61 \mathrm{X}+\mathrm{b} 62 \mathrm{Mo}+\mathrm{b} 63 \mathrm{XMo}+\mathrm{b} 64 \mathrm{Me}+\mathrm{b} 65 \mathrm{MeMo}$

(a) b43 >0; (b) b63 < b43; (c) b65 >0 and b51 >0 [see Muller et al. (2005), p. 856]

This analysis shows that the objective effort impacts perceived effort rating but the effect of perceived effort on evaluation is moderated by value focus. Limitations of this analysis in being interpreted as evidence of process are noted in the discussion of experiment 1. 


\section{APPENDIX C}

FIGURE C1

STATISTICAL CONDITIONS TEASING APART ATTRIBUTE LEVEL MODEL (A), DECISION WEIGHT MODEL (B), AND COMBINED MODEL (C) AS UNDERLYING EFFECT OF EFFORT AND FOCUS ON EVALUATION

(EXPERIMENTS 3 AND 4)

Model A

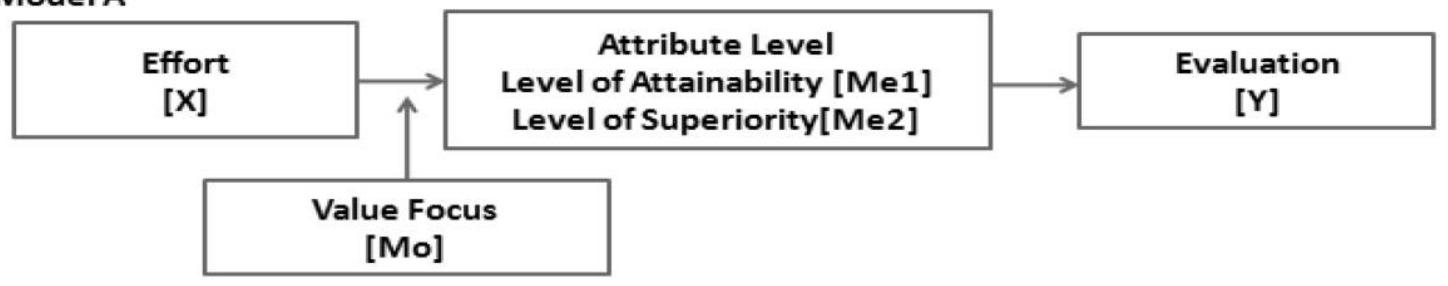

Model B

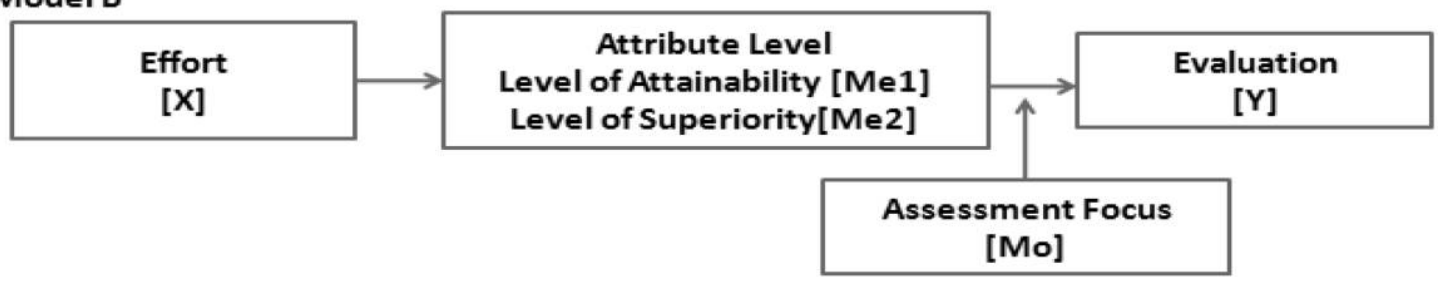

Model C

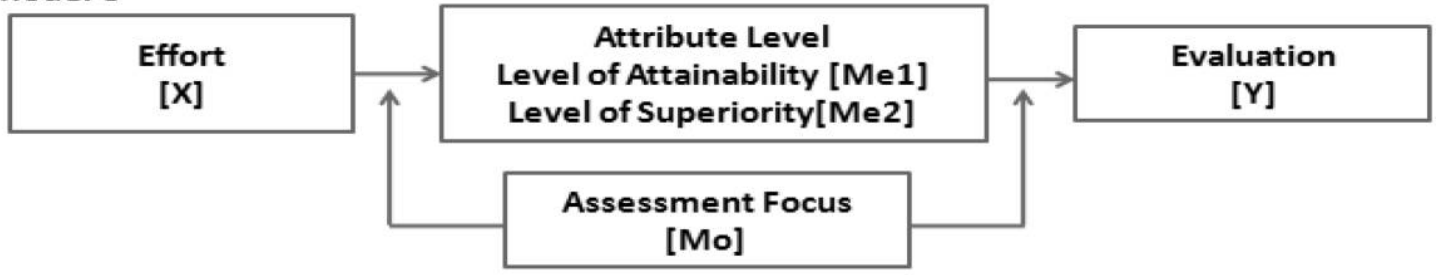

1. $\mathrm{Y}=\mathrm{b} 10+\mathrm{b} 11 \mathrm{X}+\mathrm{b} 12 \mathrm{Mo}+\mathrm{b} 13 \mathrm{XMo}$

2. $\mathrm{Me} 1=\mathrm{b} 20+\mathrm{b} 21 \mathrm{X}+\mathrm{b} 22 \mathrm{Mo}+\mathrm{b} 23 \mathrm{XMo}$

3. $\mathrm{Me} 2=\mathrm{b} 30+\mathrm{b} 31 \mathrm{X}+\mathrm{b} 32 \mathrm{Mo}+\mathrm{b} 33 \mathrm{XMo}$

4. $\mathrm{Y}=\mathrm{b} 40+\mathrm{b} 41 \mathrm{X}+\mathrm{b} 42 \mathrm{Mo}+\mathrm{b} 43 \mathrm{XMo}+\mathrm{b} 44 \mathrm{Me} 1+\mathrm{b} 45 \mathrm{Me} 1 \mathrm{Mo}+\mathrm{b} 46 \mathrm{Me} 2+\mathrm{b} 47 \mathrm{Me} 2 \mathrm{Mo}$ 
FIGURE C2

REQUIRED CONDITIONS FOR EACH MODEL OF FIGURE C1

REQUIRED CONDITIONS FOR EACH MODEL

\begin{tabular}{ccc}
\hline MODEL $A$ & MODEL B & MODEL C \\
\hline $\mathrm{b} 13>0$ & $\mathrm{~b} 13>0$ & $\mathrm{~b} 13>0$ \\
$\mathrm{~b} 23, \mathrm{~b} 33>0$ & $\mathrm{~b} 21, \mathrm{~b} 31>0$ & $\mathrm{~b} 23, \mathrm{~b} 33>0$ \\
$\mathrm{~b} 44, \mathrm{~b} 46>0$ & $\mathrm{~b} 45, \mathrm{~b} 47>0$ & $\mathrm{~b} 45, \mathrm{~b} 47, \mathrm{~b} 44, \mathrm{~b} 46>0$ \\
$\mathrm{~b} 13>\mathrm{b} 43$ & $\mathrm{~b} 13>\mathrm{b} 43$ & $\mathrm{~b} 13>\mathrm{b} 43$ \\
\end{tabular}

MODEL A: ATTRIBUTE LEVEL MODEL

Model A predicts that effort and value focus interact to predict evaluation, but this interaction effect is carried through changes in the perceived level of attainability and/or superiority [b44, b46] in line with value focus. That is, value determines the extent to which effort increases the level of attainability and superiority but decision weight on either aspect of value does not change.

\section{MODEL B: DECISION WEIGHT MODEL}

Model B predicts that effort is always interpreted as a signal of attainability or of superiority, but because value is singular function of attainability and superiority, more weight is assigned to one meaning over the other which impacts evaluation [b45Mo, b47Mo]. That is, weight a person places on attainability and superiority is impacted but levels of either do not change.

\section{MODEL C: COMBINED MODEL}

Model C predicts that focus impacts both interpretations of effort and decision weights. Thus, how effort is construed depends on the focus, and how much each interpretation impacts evaluation also depends on the focus $[\mathrm{b} 44+\mathrm{b} 45 \mathrm{Mo}, \mathrm{b} 46+\mathrm{b} 47 \mathrm{Mo}]$.

Note.-See Muller et al. $(2005,856)$.

\section{APPENDIX D}

\section{TESTING THE THREE ALTERNATIVE MODELS WITH LISREL}

1. AIC is a measure of goodness of fit of a model, and the model with the lowest AIC score is the preferred model. In our analysis, Model A has the lowest AIC score.

2. In addition, e1 and e 2 are not correlated ( $r=-0.04$, NS), so there is no multicollinearity issue among mediators. Thus, the analysis without the link between e1 and e 2 is similar to the one with the link. Here we only report models with a link between e1 and e2.

3. Models were also run using the separate items comprising attainability, superiority, and evaluation. Details are available from the corresponding author. 
FIGURE D1

TESTS FOR EXPERIMENT 3

LISREL Model A, AIC $=101.59($ Exp. 3$)$

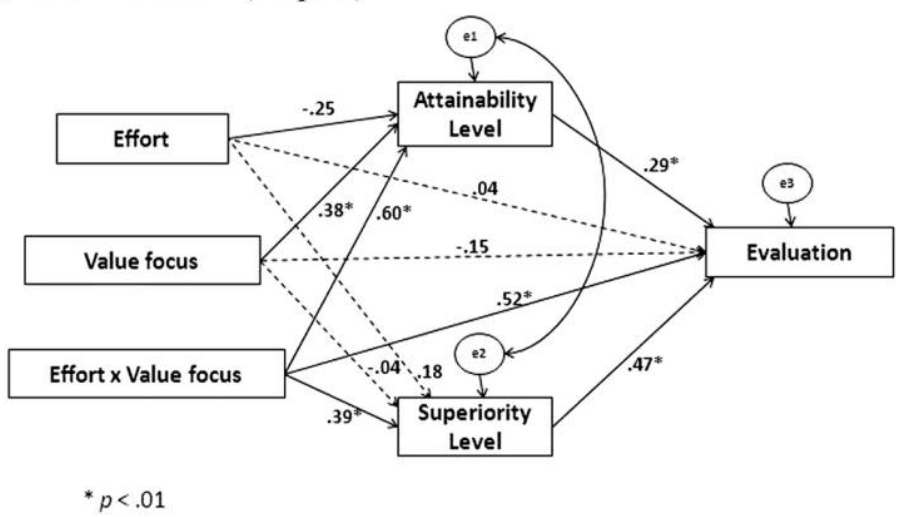

LISREL Model B, AIC $=379.09($ Exp. 3)

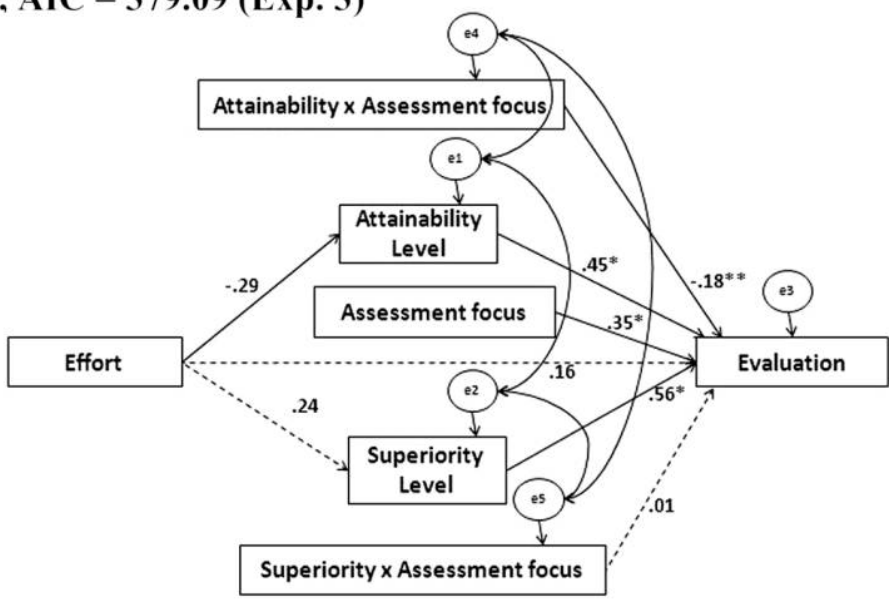

$* p<.01, * * p<.05$

LISREL Model C, AIC $=416.68($ Exp. 3)

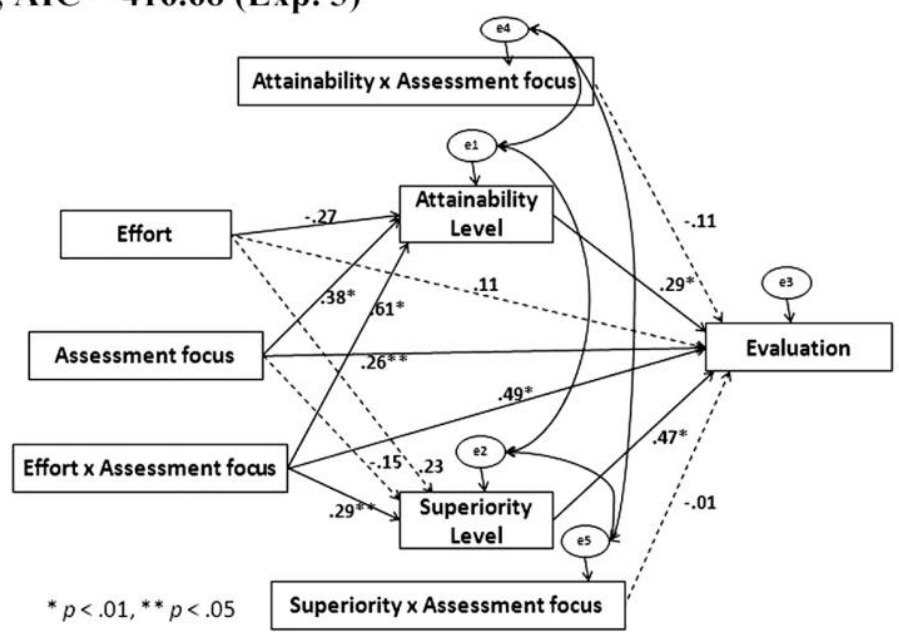


LISREL Model A, AIC $=116.10($ Exp. 4)

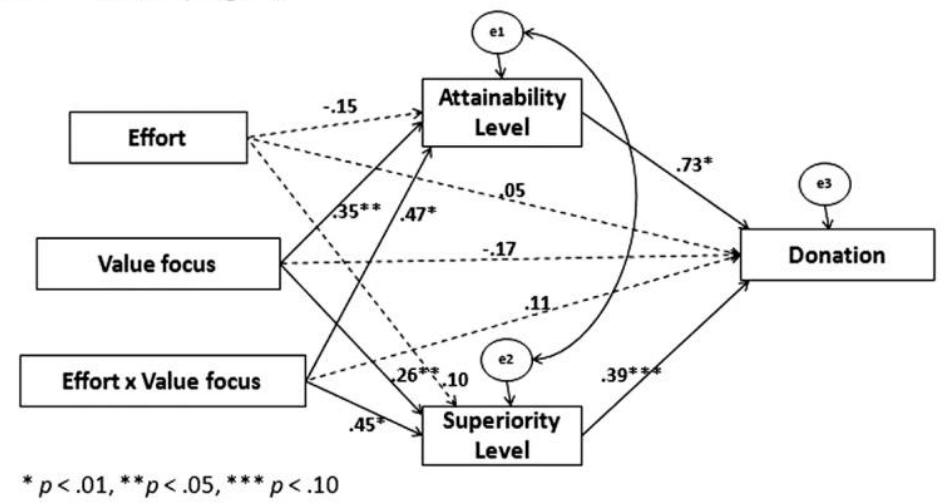

LISREL Model B, AIC $=205.72($ Exp. 4)

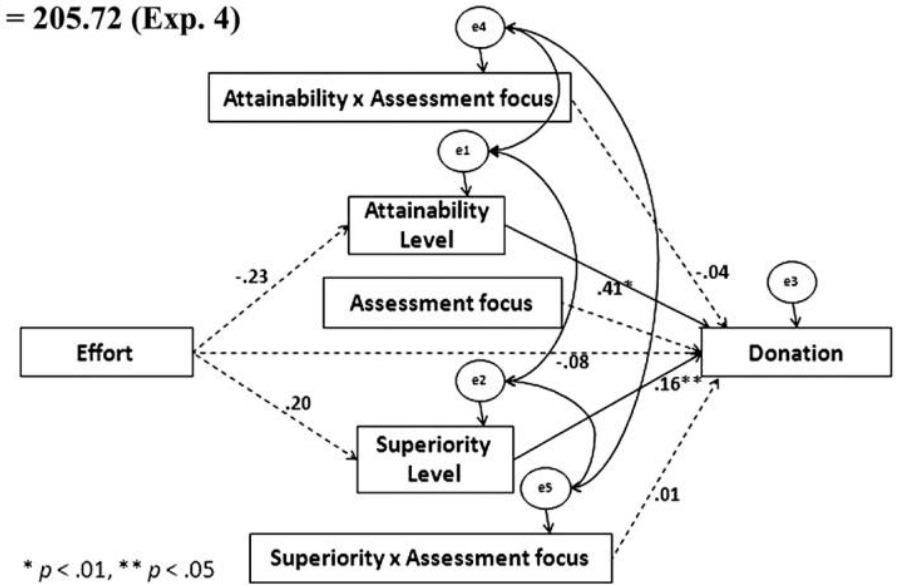

LISREL Model C, AIC = $396.04($ Exp. 4)

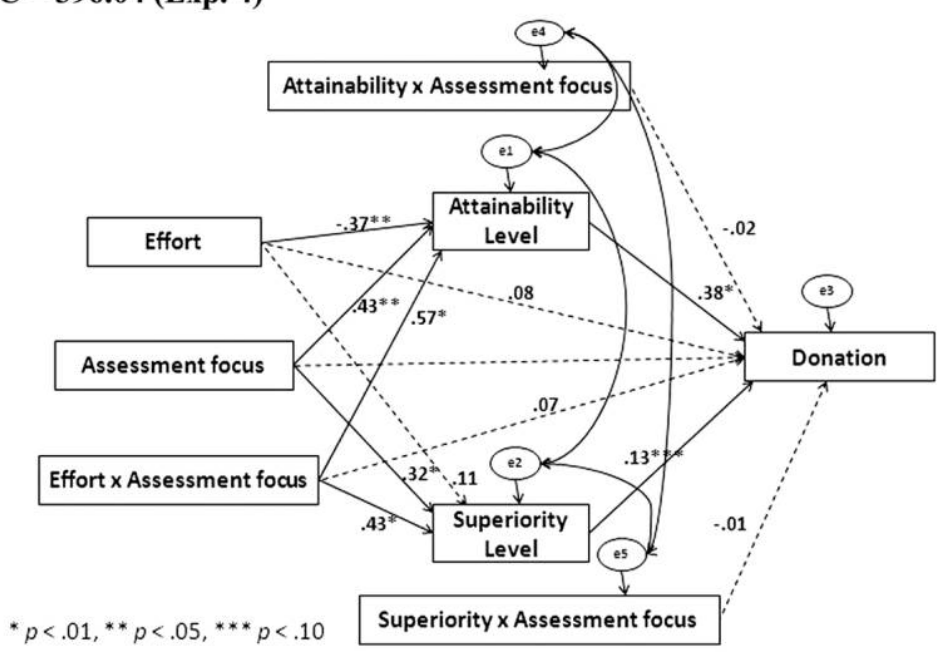




\section{APPENDIX E}

\section{TESTING MODEL A USING MULTIPLE MEDIATOR ANALYSIS (PREACHER AND HAYES 2008)}

FIGURE E1

MULTIPLE MEDIATOR CONFIGURATION
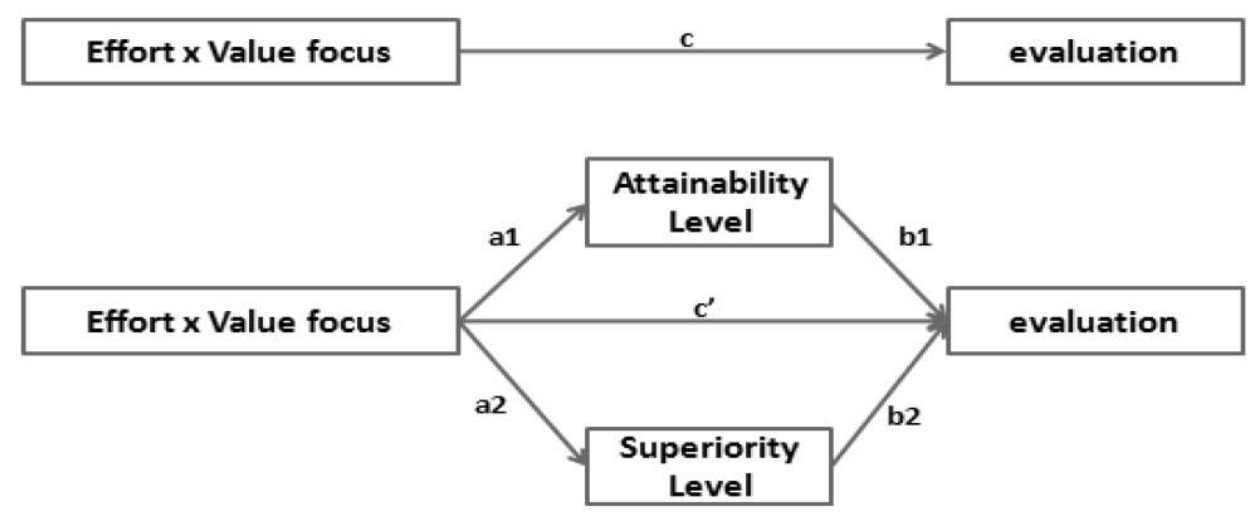

NOTE.-Effort, Focus, Attainability $\times$ Focus, and Superiority $\times$ Focus were included as covariates but are not depicted in the figure. 
TABLE E1

MULTIPLE MEDIATOR ANALYSIS RESULTS (EXPERIMENT 3)

\begin{tabular}{lrrrr}
\hline \hline & $b$ & SE & $t$ & $p$ \\
\hline IV to mediators (a paths): & & & & \\
$\quad$ Attainability (a1) & .61 & .16 & 3.89 & $<.01$ \\
$\quad$ Superiority (a2) & .31 & .15 & 2.02 & $<.05$ \\
Mediators on DV (b paths): & & & & \\
$\quad$ Attainability (b1) & .29 & .10 & 2.86 & $<.01$ \\
$\quad$ Superiority (b2) & .47 & .10 & 4.48 & $<.01$ \\
IV on DV (c path): & .81 & .14 & 5.70 & $<.01$ \\
$\quad$ Overall effect (c) & .49 & .14 & 3.60 & $<.01$ \\
$\quad$ Direct effect (c') & & & & \\
Partial effect of control variables on DV: & .11 & .13 & .84 & $>.40$ \\
$\quad$ Effort & .26 & .59 & .44 & $>.60$ \\
$\quad$ Value focus & -.11 & .10 & -1.13 & $>.20$ \\
$\quad$ Attainability x Focus & -.01 & .10 & -.05 & $>.90$ \\
$\quad$ Superiority $\times$ Focus & &
\end{tabular}

NOTE. - The $b$ paths are for the effect of mediator on the dependent variable (DV) the controlling independent variable (IV) and the other mediator. Thus, $b$ paths consider multicollinearity between the two mediators. The $c^{\prime}$ path is for the effect of the IV on the DV controlling the two mediators. Sobel $z$ attainability $=$ $2.30, p<.05$; Sobel $z$ superiority $=1.84, p=.06$.

TABLE E2

MULTIPLE MEDIATOR ANALYSIS RESULTS (EXPERIMENT 4)

\begin{tabular}{lcccc}
\hline \hline & $b$ & SE & $t$ & $p$ \\
\hline IV to mediators (a paths): & & & & \\
$\quad$ Attainability (a1) & .58 & .17 & 3.44 & $<.01$ \\
$\quad$ Superiority (a2) & .43 & .12 & 3.57 & $<.01$ \\
Mediators on DV (b paths): & & & & \\
$\quad$ Attainability (b1) & .37 & .09 & 4.09 & $<.01$ \\
$\quad$ Superiority (b2) & .22 & .11 & 1.99 & $=.05$ \\
IV on DV (c paths): & .33 & .10 & 3.28 & $<.01$ \\
$\quad$ Overall effect (c) & .02 & .10 & .21 & $>.80$ \\
$\quad$ Direct effect (c') & & & & \\
Partial effect of control variables on DV: & -.01 & .09 & -.01 & $>.90$ \\
$\quad$ Effort & -.83 & .62 & -1.34 & $=.20$ \\
$\quad$ Value focus & -.01 & .06 & -.07 & $>.90$ \\
$\quad$ Attainability x Focus & .15 & .13 & 1.16 & $>.20$ \\
$\quad$ Superiority x Focus & & & & \\
\hline
\end{tabular}

NOTE. - The $b$ paths are for the effect of mediator on the dependent variable (DV) the controlling independent variable (IV) and the other mediator. Thus, b paths consider multicollinearity between the two mediators. The $c^{\prime}$ path is for the effect of the IV on the DV controlling the two mediators. Sobel $z$ attainability $=$ 2.63, $p<.01$; Sobel $z$ superiority $=1.74, p=.08$. 


\section{APPENDIX F}

TABLE F1

MEDIATED MODERATION ANALYSES USING EACH OF THE TWO MEDIATORS INDEPENDENTLY (EXPERIMENTS 3 AND 4)

\begin{tabular}{|c|c|c|c|c|c|c|c|}
\hline Equation & Effort & Focus & $\begin{array}{l}\text { Effort } x \\
\text { focus }\end{array}$ & Attainability & $\begin{array}{l}\text { Attainability } \times \\
\text { focus }\end{array}$ & Superiority & $\begin{array}{l}\text { Superiority } \times \\
\text { focus }\end{array}$ \\
\hline \multicolumn{8}{|l|}{ Experiment 3: } \\
\hline \multirow[t]{2}{*}{ 1. Evaluation } & $\begin{array}{l}.05 \\
(.14)\end{array}$ & $\begin{array}{l}-.06 \\
(.14)\end{array}$ & $\begin{array}{l}.87^{\star \star} \\
(.14)\end{array}$ & & & & \\
\hline & [.38] & {$[-.45]$} & [6.30] & & & & \\
\hline \multirow[t]{2}{*}{ 2. Attainability } & $\begin{array}{l}-.26 \\
(.15)\end{array}$ & $\begin{array}{l}.38^{\star *} \\
(.15)\end{array}$ & $\begin{array}{l}.60^{* \star} \\
(.15)\end{array}$ & & & & \\
\hline & {$[-1.72]^{+}$} & [2.57] & [4.01] & & & & \\
\hline \multirow[t]{2}{*}{ 3. Evaluation } & $\begin{array}{l}.20 \\
(15)\end{array}$ & $\begin{array}{c}.30 \\
(43)\end{array}$ & $\begin{array}{l}.67^{\star \star *} \\
(15)\end{array}$ & $\begin{array}{r}.27^{*} \\
(11)\end{array}$ & $\begin{array}{r}-.14 \\
(12)\end{array}$ & & \\
\hline & $\begin{array}{r}(.15) \\
{[1.33]}\end{array}$ & $\begin{array}{l}(.43) \\
{[.70]}\end{array}$ & $\begin{array}{r}(.15) \\
{[4.35]}\end{array}$ & $\begin{array}{l}(.11) \\
(2301\end{array}$ & $\begin{array}{r}(.12) \\
{[-1.15]}\end{array}$ & & \\
\hline \multirow[t]{3}{*}{ 4. Superiority } & .18 & -.04 & $.39^{*}$ & & & & \\
\hline & $(.16)$ & $(.15)$ & $(.16)$ & & & & \\
\hline & [1.14] & {$[-0.25]$} & [2.47] & & & & \\
\hline \multirow[t]{3}{*}{ 5. Evaluation } & -.02 & -.03 & .69 & & & $.47^{*}$ & -.01 \\
\hline & (.12) & $(.50)$ & $*(.13)$ & & & (.11) & (.11) \\
\hline & {$[-.19]$} & {$[-.06]$} & [5.48] & & & [4.22] & {$[-.15]$} \\
\hline \multirow{4}{*}{$\begin{array}{r}\text { Experiment 4: } \\
\text { 1. Donation }\end{array}$} & & & & & & & \\
\hline & .01 & .01 & $.13^{*}$ & & & & \\
\hline & $(.04)$ & (.04) & $(.04)$ & & & & \\
\hline & {$[.27]$} & {$[.28]$} & [3.76] & & & & \\
\hline \multirow[t]{3}{*}{ 2. Attainability } & -.33 & $.43^{\star}$ & $.45^{\star}$ & & & & \\
\hline & $(.21)[$ & (.21) & $(.21)$ & & & & \\
\hline & $-1.62]$ & [2.11] & [2.20] & & & & \\
\hline \multirow[t]{3}{*}{ 3. Donation } & .04 & -.02 & $.09^{*}$ & $.10^{*}$ & .01 & & \\
\hline & $(.03)$ & $(.12)$ & (.04) & $(.03)$ & $(.03)$ & & \\
\hline & [1.23] & {$[-.15]$} & [2.54] & [3.52] & {$[.15]$} & & \\
\hline \multirow[t]{3}{*}{ 4. Superiority } & .13 & $.27^{*}$ & $.37^{\star \star}$ & & & & \\
\hline & (.12) & $(.12)$ & $(.11)$ & & & & \\
\hline & [1.07] & [2.24] & [3.36] & & & & \\
\hline \multirow[t]{3}{*}{ 5. Donation } & -.03 & -.37 & $.08^{+}$ & & & .12 * & .07 \\
\hline & $(.05)$ & $(.30)$ & $(.04)$ & & & $(.06)$ & $(.06)$ \\
\hline & {$[-.73]$} & {$[-1.21]$} & [1.82] & & & [1.89] & [1.18] \\
\hline
\end{tabular}

NOTE.-Standard errors are in parentheses; $t$-values are in brackets. Items not marked with a significance symbol are not significant. For experiment $3, n=60$, Sobel $z$ attainability $=2.09, p<.05$; Sobel $z$ superiority $=2.12, p<.05$. For experiment $4, n=36$, Sobel $z$ attainability $=1.87, p<.06$; Sobel $z$ superiority $=1.71, p=.08$. All equations included constant terms. This analysis shows that each mediator (level of attainability and level of superiority) independently provides mediated moderation.

${ }^{+} p<.10$.

${ }^{*} p<.05$.

${ }^{* *} p<.01$.

\section{REFERENCES}

Alter, Adam L. and Daniel M. Oppenheimer (2006), "Predicting Short-Term Stock Fluctuations by Using Processing Fluency," Proceedings of the National Academy of Science of the United States of America, 103 (24), 9369-72.

Bandura, Albert (1977), "Self-Efficacy: Toward a Unifying Theory of Behavioral Change," Psychological Review, 84 (2), $191-$ 215.

Bem, Daryl J. (1967), “Self-Perception: An Alternative Interpretation of Cognitive Dissonance Phenomena," Psychological Review, 74 (3), 183-200.

(1972), Self-Perception Theory, Advance in Experiment Social Psychology, New York: Academic Press.

Berridge, Kent C. (1999), "Pleasure, Pain, Desire, and Dread: Hidden Core Processes of Emotions," In Well-Being: The Foundations of Hedonic Psychology, ed, Daniel Kahneman, Paul
Slovic, and Norbert Schwarz, New York: Russell Sage Foundation, 525-57.

$\rightarrow$ Bornstein, Robert F. (1989), "Exposure and Affect: Overview and Meta-Analysis of Research, 1968-1987," Psychological Bulletin, 106 (2), 265-89.

$\rightarrow$ Botvinick, Matt M., Stacey Huffstetler, and Joseph T. McGuire (2009), "Effort Discounting in Human Nucleus Accumbens," Cognitive, Affective, and Behavioral Neuroscience, 9 (1), 16-27.

$\rightarrow$ Briñol, Pablo, Richard E. Petty, and Zakary L. Tormala (2006), "The Malleable Meaning of Subjective Ease," Psychological Science, 17 (3), 200-206.

$\rightarrow$ Bullock, John G., Donald P. Green, and Shang E. Ha (2010), "Yes, But What's the Mechanism? (Don't Expect an Easy Answer)," Journal of Personality and Social Psychology, 98 (4), 55058.

$\rightarrow$ Dai, Xianchi, C. Miguel Brendl, and Dan Ariely (2010), "Want- 
ing, Liking, and Preference Construction," Emotion, 10 (3), 324-34.

$\rightarrow$ Dai, Xianchi, Klaus Wertenbroch, and Miguel Brendl (2008) "Value as Information: The Value Heuristic in Frequency Judgments," Psychological Science, 19 (1), 18-19.

$\rightarrow$ Dhar, Ravi (1997), "Consumer Preference for a No-Choice Option Source," Journal of Consumer Research, 24 (September), 215-31.

$\rightarrow$ Duran, Robert L. (1992), "Communicative Adaptability: A Review of Conceptualization and Measurement," Communication Quarterly, 40 (3), 253-68.

$\rightarrow$ Ehrlinger, Joyce and David Dunning (2003). "How Chronic SelfViews Influence (and Potentially Mislead) Estimates of Performance," Journal of Personality and Social Psychology, 84 (1), 5-17.

Festinger, Leon (1957), A Theory of Cognitive Dissonance, Stanford, CA: Stanford University Press.

$\rightarrow$ Fishbach, Ayelet and Aparna A. Labroo (2007), "Be Better or Be Merry: How Mood Affects Self-Control," Journal of Personality and Social Psychology, 93 (2), 158-73.

$\rightarrow$ Frederick, Shane, Nathan Novemsky, Jing Wang, Ravi Dhar, and Stephen Nowlis (2009), "Opportunity Cost Neglect," Journal of Consumer Research, 36 (December), 533-61.

$\rightarrow$ Fujita, Kentaro, Yaacov Trope, Nira Liberman, and Maya LevinSagi (2006), "Construal Levels and Self-Control," Journal of Personality and Social Psychology, 90 (3), 351-67.

$\rightarrow$ Galak, Jeff and Leif D. Nelson (2011), "The Virtues of Opaque Prose: How Lay Beliefs about Fluency Influence Perceptions of Quality," Journal of Experimental Social Psychology, 47 (1), 250-53.

$\rightarrow$ Gollwitzer, Peter M. and Ronald F. Kinney (1989), "Effects of Deliberative and Implemental Mind-Sets on Illusion of Control," Journal of Personality and Social Psychology, 56 (4), 531-42.

Hedgcock, William and Akshay R. Rao (2009), "Trade-Off Aversion as an Explanation for the Attraction Effect: A Functional Magnetic Resonance Imaging Study," Journal of Consumer Research, 46 (1), 1-13.

$\rightarrow$ Iyengar, Sheena S. and Mark R. Lepper (2000), "When Choice Is Demotivating: Desiring Too Much of a Good Thing," Journal of Personality and Social Psychology, 79 (6), 995-1006.

$\rightarrow$ Kivetz, Ran and Itamar Simonson (2002), "Earning the Right to Indulge: Effort as a Determinant of Customer Preferences towards Frequency Program Rewards," Journal of Marketing Research, 39 (2), 155-70.

$\rightarrow$ _ (2003), "The Idiosyncratic Fit Heuristic: Effort as a Determinant of Consumer Response to Loyalty Programs," Journal of Marketing Research, 40 (4), 454-67.

$\rightarrow$ Kruger, Justin and David Dunning (1999), "Unskilled and Unaware of It: How Difficulties in Recognizing One's Own Incompetence Lead to Inflated Self-Assessments," Journal of Personality and Social Psychology, 77 (6), 1121-34.

$\rightarrow$ Kruger, Justin, Derrick Wirtz, Leaf Van Boven, and T. William Altermatt (2004), "The Effort Heuristic," Journal of Experimental Social Psychology, 40 (1), 91-98.

$\rightarrow$ Labroo, Aparna A., Ravi Dhar, and Norbert Schwarz (2008), "Of Frowning Watches and Frog Wines: Semantic Priming, Perceptual Fluency, and Brand Evaluation," Journal of Consumer Research, 34 (April), 819-31.

$\rightarrow$ Labroo, Aparna A. and Sara Kim (2009a), "The "Instrumentality" Heuristic: Why Metacognitive Difficulty Is Desirable during Goal Pursuit," Psychological Science, 20 (1), 127-34.

$\rightarrow$ _ (2009b), "When the Going Gets Tough: How Metacog- nitive Difficulty Improves Evaluation," Advances in Consumer Research, 36, 8-11.

$\rightarrow$ Labroo, Aparna A., Soraya Lambotte, and Yan Zhang (2009), "The 'Name-Ease' Effect and Its Dual Impact on Importance Judgments," Psychological Science, 20 (12), 1516-22.

$\rightarrow$ Labroo, Aparna A. and Angela Y. Lee (2006), "Between Two Brands: A Goal Fluency Account of Brand Evaluation," Journal of Marketing Research, 43 (3), 374-85.

$\rightarrow$ Langer, Ellen J. (1975), "The Illusion of Control," Journal of Personality and Social Psychology, 32 (2), 311-28.

$\rightarrow$ Lee, Angela Y. and Aparna A. Labroo (2004), "The Effect of Conceptual and Perceptual Fluency on Brand Evaluation," Journal of Marketing Research, 41 (May), 151-65.

$\rightarrow$ Litt, Ab, Uzma Khan, and Baba Shiv (2010), "Lusting While Loathing: Parallel Counterdriving of Wanting and Liking," Psychological Science, 21 (1), 118-25.

$\rightarrow$ Lo, Alison K. C., John G. Lynch Jr., and Richard Staelin (2007), "How to Attract Customers by Giving Them the Short End of the Stick," Journal of Marketing Research, 44 (1), 12841

$\rightarrow$ Luce, Mary Frances, John W. Payne, and James R. Bettman (1999), "Emotional Trade-Off Difficulty and Choice," Journal of Marketing Research, 36 (2), 143-59.

Mallalieu, Lynnea and Kay M. Palan (2006), "How Good a Shopper Am I? Conceptualizing Teenage Girls' Perceived Shopping Competence," Academy of Marketing Sciences Review, No. 5, 1-28.

$\rightarrow$ Miele, David B. and Daniel C. Molden (2010), "Naive Theories of Intelligence and the Role of Processing Fluency in Perceived Comprehension," Journal of Experimental Psychology: General, 139 (3), 535-57.

$\rightarrow$ Muller, Dominique, Charles M. Judd, and Vincent Y. Yzerbyt (2005), "When Moderation Is Mediated and Mediation Is Moderated," Journal of Personality and Social Psychology, 89 (6), 852-63.

$\rightarrow$ Naqvi, Nasir, Baba Shiv, and Antoine Bechara (2006), "The Role of Emotion in Decision Making: A Cognitive Neuroscience Perspective," Current Directions in Psychological Science, 15 (5), 260-64.

Payne, John W., James R. Bettman, and Eric J. Johnson (1993), The Adaptive Decision Maker, Cambridge: Cambridge University Press.

Pocheptsova, Anastasiya, Aparna A. Labroo, and Ravi Dhar (2011), "Making Products Feel Special: When Metacognitive Difficulty Improves Product Evaluation," Journal of Marketing Research, forthcoming.

$\rightarrow$ Preacher, Kristopher J. and Andrew F. Hayes (2008), "Asymptotic and Resampling Strategies for Assessing and Comparing Indirect Effects in Multiple Mediator Models," Behavior Research Methods, 40 (3), 879-91.

$\rightarrow$ Preacher, Kristopher, Derek D. Rucker, and Andrew F. Hayes (2007), "Addressing Moderated Mediation Hypotheses: Theory, Methods, and Prescriptions," Multivariate Behavioral Research, 42 (1), 185-227.

$\rightarrow$ Reber, Rolf, Piotr Winkielman, and Norbert Schwarz (1998), "Effects of Perceptual Fluency on Affective Judgments," Psychological Science, 9 (1), 45-48.

Schrift, Rom Y., Oded Netzer, and Ran Kivetz (2011), "Complicating Choice," Journal of Marketing Research, forthcoming.

$\rightarrow$ Schwarz, Norbert (2004), "Metacognitive Experiences in Consumer Judgment and Decision Making," Journal of Consumer Psychology, 14 (4), 332-48.

Sela, Aner and Jonah Berger (2011), "Decision Quicksand: When 
Trivial Choices Suck Us In,” Working Paper, Department of Marketing, Warrington College of Business, University of Florida.

$\rightarrow$ Sela, Aner, Jonah Berger, and Wendy Liu (2009), "Variety, Vice, and Virtue: How Assortment Size Influences Option Choice," Journal of Consumer Research, 35 (6), 941-51.

Simonson, Itamar (1989), "Choice Based on Reasons: The Case of Attraction and Compromise Effects Source," Journal of Consumer Research, 16 (September), 158-74.

Soman, Dilip (1998), "The Illusion of Delayed Incentives: Evaluating Future Effort-Money Transactions," Journal of Marketing Research, 35 (4), 427-37.

$\rightarrow$ Staw, Barry M. (1981), "The Escalation of Commitment to a Course of Action," Academy of Management Review, 6 (4), 577-87.

Taylor, Shelley E. and Jonathon D. Brown (1988), "Illusion and Well-Being: A Social Psychological Perspective on MentalHealth," Psychological Bulletin, 103 (2), 193-210.

Thompson, Debora Viana, Rebecca W. Hamilton, and Petia K. Petrova (2009), "When Mental Simulation Hinders Behavior: The Effects of Process-Oriented Thinking on Decision Difficulty and Performance," Journal of Consumer Research, 36 (4), 562-74.

$\rightarrow$ Tsai, Claire I. and Ann L. McGill (2011), "No Pain, No Gain? How Fluency and Construal Level Affect Consumer Confidence," Journal of Consumer Research 37 (5), 807-21. $\rightarrow$ Wänke, Michaela, Gerd Bohner, and Andreas Jurkowitsch (1997), "There Are Many Reasons to Drive a BMW: Does Imagined Ease of Argument Generation Influence Attitudes?" Journal of Consumer Research, 24 (2), 170-78.

$\rightarrow$ Whittlesea, Bruce W. A. (1993), "Illusions of Familiarity," Journal of Experimental Psychology: Learning, Memory, and Cognition, 19 (6), 1235-53.

$\rightarrow$ Wilkie, William L. and Edgar A. Pessemier (1973), "Issues in Marketing's Use of Multi-Attribute Attitude Models," Journal of Marketing Research, 10 (4), 428-41.

Winer, Benjamin J. (1971), Statistical Principles in Experimental Design, New York: McGraw-Hill.

$\rightarrow$ Winkielman, Piotr and Kent Berridge (2003), "Irrational Wanting and Subrational Liking: How Rudimentary Motivational and Affective Processes Shape Preferences and Choices," Political Psychology, 24 (4), 657-80.

$\rightarrow$ Winkielman, Piotr and John T. Cacioppo (2001), "Mind at Ease Puts a Smile on the Face: Psychophysiological Evidence That Processing Facilitation Elicits Positive Affect," Journal of Personality and Social Psychology, 81 (6), 989-1000.

$\rightarrow$ Yeung, Catherine W. M. and Dilip Soman (2007), "The Duration Heuristic," Journal of Consumer Research, 34 (October), 315-26.

$\rightarrow$ Zajonc, Robert B. (1968), "Attitudinal Effects of Mere Exposures," Journal of Personality and Social Psychology, 9 (2), 1-27. 